Florida International University FIU Digital Commons

$11-25-1998$

\title{
Occupational therapists' assessment of the caregivers of their elderly patients
}

Ernest Vincent Corradetti

Florida International University

DOI: $10.25148 /$ etd.FI14061519

Follow this and additional works at: https://digitalcommons.fiu.edu/etd

Part of the Occupational Therapy Commons

\section{Recommended Citation}

Corradetti, Ernest Vincent, "Occupational therapists' assessment of the caregivers of their elderly patients" (1998). FIU Electronic Theses and Dissertations. 2587.

https://digitalcommons.fiu.edu/etd/2587

This work is brought to you for free and open access by the University Graduate School at FIU Digital Commons. It has been accepted for inclusion in FIU Electronic Theses and Dissertations by an authorized administrator of FIU Digital Commons. For more information, please contact dcc@fiu.edu. 


\section{FLORIDA INTERNATIONAL UNIVERSITY}

Miami, Florida

\section{OCCUPATIONAL THERAPISTS' ASSESSMENT OF THE CAREGIVERS OF THEIR ELDERLY PATIENTS}

A thesis submitted in partial fulfillment of the

requirements for the degree of

MASTER OF SCIENCE

in

OCCUPATIONAL THERAPY

by

Ernest Vincent Corradetti 
To: Dean DeLois P. Weekes College of Health Sciences

This thesis, written by Ernest Vincent Corradetti, and entitled Occupational Therapists' Assessment of The Caregivers of Their Elderly Patients, having been approved in respect to style and intellectual content, is referred to you for judgement.

We have read this thesis and recommend that it be approved.

Michael P. Brady

Paulette Johnson

Gail Ann Hills, Major Professor

Date of Defense: November 25, 1998

The thesis of Ernest Vincent Corradetti is approved.

Dean DeLois P. Weekes College of Health Sciences

Dean Richard L. Campbell Division of Graduate Studies

Florida International University, 1998 


\section{DEDICATION}

I dedicate this thesis to my parents, Michael and Angeline. Their love, devotion, emotional, and financial support, coupled with their belief and love for higher education have made this possible. 


\section{ACKNOWLEDGEMENTS}

I wish to thank all of the members of my committee for their time, direction, and patience. Specifically, I would like to extend my appreciation to Dr. Gail Ann Hills for her time, expertise, and mentoring throughout my graduate program. A special thanks to Dr. Paulette Johnson for her smiles, humor, and ability to make sense out of twelve pounds of statistical printouts. I would also like to congratulate Dr. Michael Brady for being able to stay out of the water long enough to attend my defense. Seriously, Doc, thanks for the encouragement when I was down, having answers at odd hours, and the time to respond to countless questions. 


\author{
ABSTRACT OF THE THESIS \\ OCCUPATIONAL THERAPISTS' ASSESSMENT OF THE \\ CAREGIVERS OF THEIR ELDERLY PATIENTS \\ by \\ Ernest Vincent Corradetti \\ Florida International University, 1998 \\ Miami, Florida \\ Professor Gail Ann Hills, Major Professor
}

The purpose of this study was to determine the methods and extent to which occupational therapists who are practicing in aging are assessing the caregivers of their elderly patients. A random sample of 500 therapists who subscribe to a special interest group publication of a professional organization were surveyed by mail and 204 responses were received.

Respondents were asked to indicate all of the activities related to caregiver assessments in which they engage. Methods of assessment included: (a) professional caregiving activities, (b) informal assessment methods, and (c) formal assessment methods. There were more than $90 \%$ of respondents who indicated that they engaged in at least two professional 
activities related to caregiving, such as patient and/or caregiver education and discharge planning. Approximately one-third of subjects indicated that formal assessment is performed with a facility created assessment cited as the most frequently used formal instrument. Informal assessment methods were used by all but one subject in the sample. Direct questioning/discussion with caregiver and observation of the caregiver were the most frequently used informal assessment methods at $90 \%$ and $93.6 \%$, respectively.

The findings indicate that virtually all occupational therapists are highly engaged in assessing the caregivers of their elderly patients. Most of the assessment being performed relies on their clinical expertise and observation and/or facility created assessments. Furthermore, clinicians are highly engaged in patient and/or caregiver education. It is recommended that more of the body of research related to formal multidimensional caregiver assessment be disseminated into the occupational therapy community. 
CHAPTER





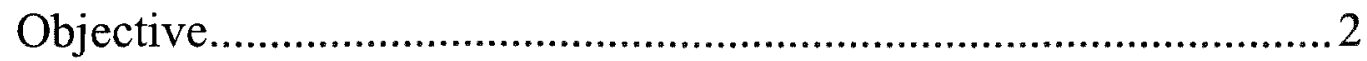

Objective and Hypothesis .............................................................. 2

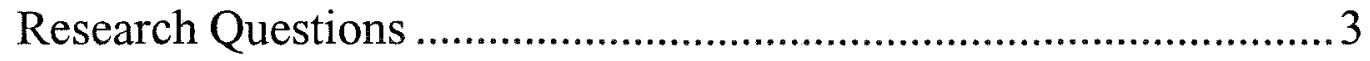

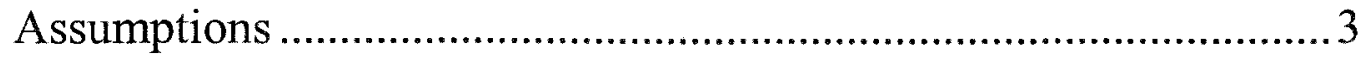



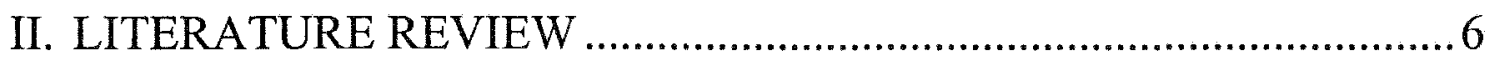

Burden ........................................................................................

Relationship Between Caregiver Burden and Activities of

Daily Living ......................................................................... 10

Caregiver Burden and Depression ..................................................11

Caregiver Burden, Gender, and Coping Strategies............................12

Caregiver Burden and Institutionalization of the Carereceiver........13

Caregiving Models ........................................................................ 14

Assessing Caregiver Burden ...........................................................20

Global Assessment and Multidimensional Assessment ..................21

Assessment of Burden in Spousal Caregivers ..................................22

Assessment of Burden in Non-Spousal Caregivers ..........................24

Assessment of Burden: Caregiver of an Older Adult .......................2.25

Assessment of Depression................................................................26

Multidimensional Caregiver Assessment Instruments ....................29

Social Assessment of Caregivers .................................................... 31

Resource for Caregiver Burden Assessments (Mentally I11) ...........32

Questionnaire as a Research Method .................................................34

Summary of the Literature ................................................................. 35

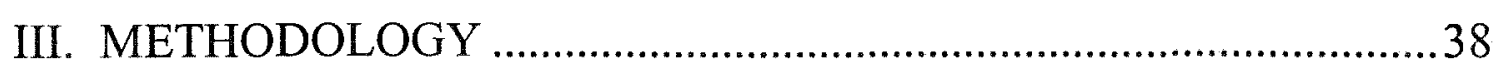

Objectives and Research Questions ...............................................38

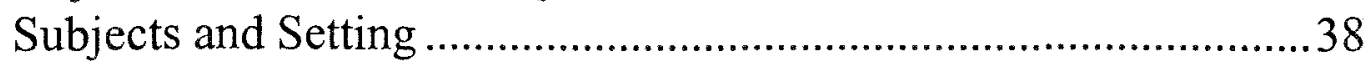





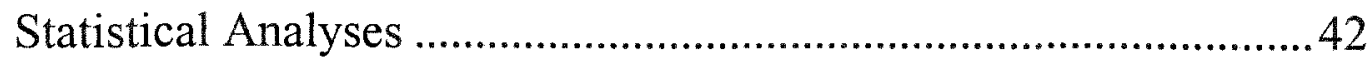

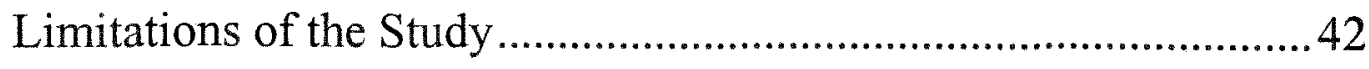








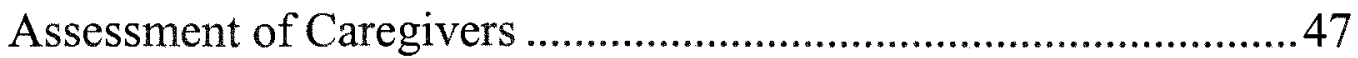

Professional Caregiving Activities .................................................48

Formal Caregiver Assessment Tools .............................................49

Therapist Rationales for Not Using Formal Caregiver Assessment 51

Multidimensional Caregiver Assessments......................................55

Familiarity with Ten Formal Multidimensional Assessment Tools 55

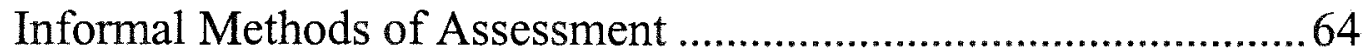

Clinical Experience, Education, and Employment Setting ..............65

Employment Setting and Type of Caregiver Assessment ................68

Level of Education and Type of Caregiver Assessment....................70

Level of Education and Formal Caregiver Assessment..................... 70

Education and Formal Assessment of Caregivers in the Skilled

Practice Setting........................................................................... 71

Education, Employment Setting, Years of Experience, and

Informal Assessment ................................................................... 73

Employment Setting, Total Years in Occupational Therapy, and

Total Years in Aging ................................................................... 74

Issues Important to Clinicians..........................................................

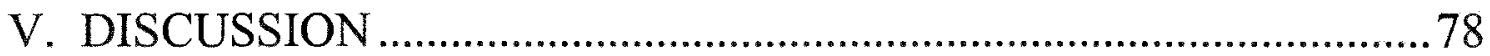

Professional Caregiving Activities .............................................79

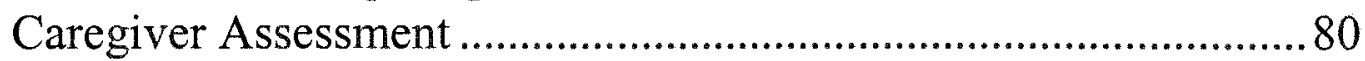

Formal Multidimensional Caregiver Assessment............................81

Educational Level and Clinical Experience of the

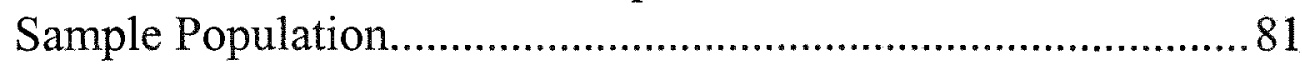

Employment Setting and Caregiver Assessment............................. 82

The Beck Depression Inventory .....................................................83

Education, Employment Setting, Years of Experience, and

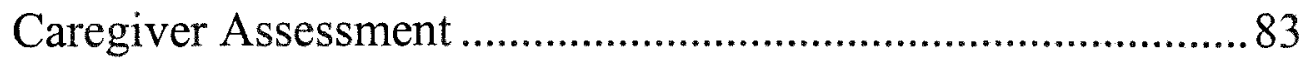

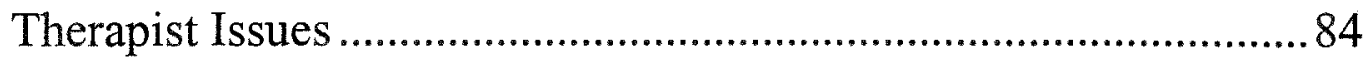





APPENDIX 


\section{LIST OF TABLES}

1. Subject Geographic Region of Practice .................................................46

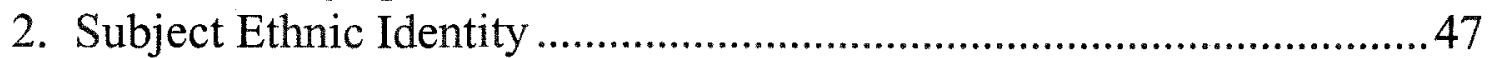

3. Professional Activities Related to Caregiving ......................................49

4. Formal Caregiver Assessment Methods ................................................51

5. Therapist Rationales for Not Using Formal Caregiver Assessment.....53

6. Frequency of Use of Multidimensional Caregiver Assessments...........59

7. Informal Caregiver Assessment Methods ...............................................65

8. Number of Years in Practice by Highest Degree in OT .......................67

9. Number of Years in Practice by Highest Degree in Any Field ..............68

10. Use of the Beck Depression Inventory in Skilled Nursing Facilities and Hospitals by Highest Degree in Any Field ................................ 73

11. Correlations of Use of Type of Informal Assessment by Number of Years of Experience in Occupational Therapy ..................................74

12. Total Years in Aging by Employment Setting.......................................75

13. Issues and Changes in Clinical Practice.............................................. 77 


\section{Introduction}

Many adults find themselves participating in the role of caregiver to an elderly family member who resides within the community. Numerous assessment tools are available which assess the dimensions and levels of perceived burden, stress, strain and depression of the caregiver, which is attributable to the caregiving role. The majority of these assessments are designed for caregivers of the elderly with dementia, and more specifically, dementia of the Alzheimer's type.

Statement of the Problem

Many assessments of caregivers have been developed to assess perceived burden, stress, strain and depression, which are derived from caring for an elder with or without dementia. Some of these assessments are global in nature, while others are multidimensional. This study is unique in that it surveys the extent to which occupational therapists, currently giving direct delivery of services to the elderly, assessed their caregivers and identified which assessments were utilized. Voluminous amounts of general research have been conducted regarding caregiver burden, but little research has focused on the identification of precisely which assessments 
occupational therapists (OTs) use to assess caregivers. Since many of the currently available assessment tools measure perceived burden in caregivers of elders with dementia, expecting burden may cue negative responses.

George and Gwyther (1986) suggest that attitudes toward caregiver burden may be viewed antithetically as a dimension of well-being or satisfaction.

\section{Objective}

While volumes of current literature cite the need to assess the caregiving entity within the caregiving dyad (Hills, 1997; Keady, 1996) and the need for occupational therapists to use multidimensional caregiver assessment tools (Deimling, 1994), there seems to be little information which indicates the extent to which occupational therapists in clinical practice use multidimensional assessment tools when assessing the caregivers of the elderly in the community.

\section{Objective and Hypotheses}

The objective of this research was to identify the extent to which occupational therapists employed in direct patient treatment of the elderly are assessing their caregivers and to determine which tools are being used. 
It was hypothesized that a random sample of registered occupational

therapists will: (a) identify the extent to which multidimensional assessment is used in assessing the presence of burden of caregivers of the elderly, and

(b) identify which instruments are being used.

Research Questions

The research questions answered in this study were:

1. To what extent are occupational therapists (OTs) who are currently employed in direct patient contact with the elderly assessing their caregivers?

2. Which assessments are being used?

Assumptions

It is assumed that:

1. Occupational therapists will truthfully respond to the survey questions.

2. Caregivers will respond truthfully to the OTs' method(s) of assessment/questioning.

Definitions

Caregiving- caring for and/or assisting a disabled, frail, or elderly family member or spouse. 
Caregiver - the individual who provides the care and/or assistance.

Elderly relatives and carereceivers - those individuals receiving the

care and/or assistance.

Dyad or caregiving dyad - the caregiver and the carereceiver, as a

unit.

Family - encompasses anyone living separately or within the same household as the caregiver and/or carereceiver, or who is affected in some way via their association or ties with the caregiver or carereceiver.

Formal caregiving - caregiving which is performed as a paid service.

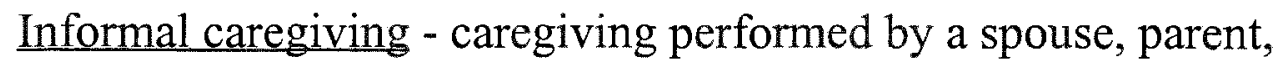
family member or friend, which is performed as a non-paid service or duty. Assessment tool - a series of questions or statements which require the respondent (caregiver) to provide an answer or rating in response to the question or statement. The assessment tool may or may not be a standardized instrument.

Multidimensional assessment - an instrument which probes more than one domain or aspect and yields a separate score or rating for each domain. 
Global assessment - an instrument which probes one or more

domains and yields a single, unified score or rating.

Caregiver burden - the caregiver's perceptions of stress, strain, depression, physical illness and/or economic strain.

Occupational therapist - an individual who has been trained as and licensed to perform occupational therapy. 


\section{Chapter II}

\section{Review of the Literature}

Current literature on the assessment of caregivers and caregiver burden can be organized into at least five areas: (a) the level of stress perceived by the caregiver (Pearson, 1986; Semple, 1992), (b) the personality traits of the caregiver as a determinant of burden (Reis, Gold, Andres, \& Markiewicz, 1994), (c) caregiver and environmental variables (Burgener, Jirovec, Murrell \& Barton, 1992), (d) caregiver burden as related to decreased social activity (Miller \& Montgomery, 1990), and (e) posthospital support programs for the elderly and their caregivers (Oktay \& Volland, 1990).

Three recent studies which look at different aspects of caregiving are those of Rankin and colleagues (1992), Skaff and Pearlin (1992), and Fredman and Daly (1997). Rankin et al. (1992) view assessment as being a process which involves the entire family: caregiver, carereceiver, and all other members of the family. The work of Skaff and Pearlin (1992) focuses on role engulfment and its effects on mastery and self-esteem of the caregiver. Fredman and Daly (1997) incorporate an additional dynamic: the 
relationship between the involved parties. As such, this literature review will focus on

(a) burden, (b) the relationship between caregiver burden and activities of daily living, (c) caregiver burden and depression, (d) caregiver burden, gender, and coping strategies, and (e) caregiver burden and institutionalization of the caregiver. The major theoretical models of caregiving and appropriate instruments for assessing a caregiver and presented.

Burden

A considerable amount of research in caregiving has focused on what stressors caregivers have stated as having had the greatest impact on their lives. These studies have attempted to isolate specific situations or events which precipitate burden in the caregivers' lives, often with conflicting findings. Clair, Fitzpatrick, and Gory (1995) espoused that burden is foremost a province of chronic stressors (activities of daily living and instrumental activities of daily living) and depression is the product of acute stressors (caregiver life events). Brown (1966) differentiated between objective and subjective burden. Patient initiated social disturbances result in objective burden, while the manifestation of these social disturbances by 
other individuals is deemed subjective burden. George and Gwyther (1986)

posed that many of the measures of caregiver burden may also be viewed conversely as dimensions of well-being or satisfaction. It is their contention that measuring caregivers' well-being, rather than measuring their burden may identify caregivers who are undergoing difficulties. Furthermore, George and Gwyther (1994) found that caregivers contrast from noncaregivers on numerous dimensions including physical health, mental health, social activities and financial picture.

Winslow (1997) conducted a study that consisted of a convenience sample of 452 spousal and adult child caregivers of individuals with Alzheimer's disease (AD). Winslow's (1997) data analysis suggested that decreased physical health of the caregiver was best explained by caregiver overload.

Pariante (1997) examined the impact of chronic psychological stress on the immune system. Eighteen female caregivers of people with disabilities and 18 age and sex-matched controls were included in the research. Pariante (1997) assessed the number and function of T-cells (T cells, $\mathrm{T}$ helper cells, and $\mathrm{T}$ suppressor/cytotoxic cells), antibody titers for latent herpes viruses, and markers of inflammation. This research 
demonstrated that the caregivers had a significantly lower $\mathrm{T}$

helper:suppressor ratio compared to their respective controls. From this, Pariante (1997) concluded that psychological stress affects various aspects of the immune system.

Caregiver life events are of sufficient magnitude as to impact the caregiver's life in some fashion. Ory and others (1985) found that a patient's severity of illness, which included measures of cognitive status and problems in functioning, was not correlated with caregiver burden, while Grad and Sainsbury (1968) and Deimling and Bass (1986) discovered that the level of confusion in the patient was a factor in predicting caregiver burden. However, delivering care to an aging family member who, more likely than not, is experiencing some form of dementia, should not be a unilateral activity; rather, it should be an interactive process (Burgener, Jirovec, Murrell, \& Barton, 1992). Perhaps these contradictory findings are the consequence of taking a reductionist view of caregiving, as opposed to viewing the process as being one that is interactive between the caregiver, the carereceiver and the family unit. Rankin and others (1992) explained that this phenomenon is due to the lack of a model that integrates both the developmental theory and the family systems theory. 
Relationship Between Caregiver Burden and Activities of Daily Living

Numerous studies have been conducted which explore the relationship between caregiver burden and activities of daily living (ADLs). Assistance in ADLs includes assistance in the daily activities in which one engages to care for oneself, such as dressing, hygiene, grooming and toileting, while instrumental activities of daily living (IADLs) include activities such as scheduling appointments, balancing one's checkbook, shopping and meal planning (Hills, 1997). Hooyman, Gonyea, and Montgomery (1985) have elucidated that caregiver burden is directly related to the number of ADLs the caregiver must aid the carereceiver to perform. Furthermore, Jones and colleagues (1996) studied a convenience sample of 93 caregiving dyads. The researchers specifically probed whether or not a relationship existed between the cognitive functioning, ADL performance, and IADL performance of the carereceivers and caregivers' reported levels of strain, as measured by the Caregiver Strain Index. Marchi-Jones and associates (1996) reported that the positive relationship between carereceivers' impairment and caregivers' strain were statistically significant. Fredman and Daly (1997) have also espoused that a direct relationship exists between the number of ADLs which caregivers must 
assist their carereceivers to perform and level of caregivers' burden. Given this phenomenon, a complete caregiver assessment should include measures of carereceivers' mental status, carereceivers' level of ADL/IADL functioning and measures of perceived stress and/or burden experienced by caregivers (Fredman \& Daly, 1997). Hawkins (1996) conducted a study to identify stressors experienced by caregiving daughters of frail, elderly parents and the coping skills used to manage those stressors. Hawkins' (1996) findings included: (a) employed caregiving daughters had significantly higher stress scores than unemployed caregiving daughters and

(b) there was no significant relationship between caregiver stress scores and ADL and IADL performance of the carereceiver. While the relationship between level of carereceiver ADL/IADL performance and level caregiver burden may be debated, it would certainly behoove the clinician to consider the possibility of the presence of caregiver burden, especially when the carereceiver requires $\mathrm{ADL} / \mathrm{IADL}$ assistance.

\section{Caregiver Burden and Depression}

The prevalence of depression among caregivers is well documented (Given, Given, Helms, Stommel \& DeVoss, 1997; Malone-Beach \& Zarit, 1995; Baumgarten et al., 1994; Bergman-Evans, 1994). Bergman-Evans 
(1994) cite a health profile of spousal caregivers of individuals affected by

Alzheimer's disease which indicates that even though an individual with

$\mathrm{AD}$ may be institutionalized, the spouse/caregiver is still at risk of suffering from depression. Furthermore, since depression is quite prevalent in caregivers across varying carereceiver diagnoses, a screening for depression should be a part of a comprehensive dyadic assessment (Malone-Beech, 1995; Gallo, 1995).

\section{Caregiver Burden, Gender, and Coping Strategies}

Several researchers have searched for a relationship between the gender of the caregiver and the caregiver's level of burden. Lutzky and Knight (1994) stated that in previous studies, female caregivers generally reported more distress than did male caregivers. The researchers offered two explanations for the reported difference. Lutzky and Knight (1994) proposed:

(a) a model which hypothesizes that male caregivers are less likely to be attentive to their emotions and fail to recognize and report distress, or (b) a model which hypothesizes that women are socialized to use coping styles that are less effective for alleviating distress. In opposition to these two hypotheses are the findings of Saad and colleagues (1995) which explored 
the coping strategies used by men and women. The work of these

researchers demonstrated that there were no significant differences between the coping strategies used by men and women.

\section{Caregiver Burden and Institutionalization of the Carereceiver}

A caregiver is often faced with making decisions that affects not only her life, but also the life of the carereceiver and the lives of other family members. One decision, which often presents the caregiver with conflicting feelings and guilt, is the decision that she can no longer perform the caregiving tasks for her loved one. Mittelman, Ferris, Shulman, Steinberg and Levin (1996) proposed that a program of counseling and support can substantially increase the time spousal caregivers are able to care for $\mathrm{AD}$ patients at home, particularly in the early to middle stages of dementia.

Freedman and associates (1994) espouse that for men, the spousal caregiver is the most important factor in reducing the risk of institutional placement, while for women, having regular contact with at least one family member of any relation reduces the risk of institutionalization.

Tsuji, Whalen, and Finucane (1995) conducted a study via a retrospective chart review. The sample $(n=334)$ of homebound patients were part of an Elder Housecall Program (EHP) between 1986 and 1989 at Johns 
Hopkins Geriatrics Center. The independent variables of their study included age, gender, diagnosis, functional status, and caregiver conditions. The dependent variable was nursing home placement of the carereceiver. The researchers' analysis revealed that significant predictors of nursing home placement included diabetes mellitus, bowel incontinence, and three caregiver characteristics: (a) living separate from the patient, (b) time conflicts/constraints due to employment, and (c) stress attributable to caregiving.

Boaz and Muller (1994) assembled data from the National LongTerm Care Surveys of 1982 and 1984. The researchers used the 1982 data to identify community-dwelling elders, and the 1984 data to assess continued residence within the community. Statistical analysis revealed that, after controlling for the effects of physical and cognitive functioning, adequate help in the community reduces the risk of permanent nursing home residence.

\section{Caregiving Models}

ABCX model of caregiving. While several models of caregiving and its effects on the family unit have been proposed, the common denominator is that all support the multidimensionality of caregiving. Rankin and 
colleagues (1992) refer to Hill's 1958 work of the conception of the

" $\mathrm{ABCX}$ " model to identify four variables and the interplay among them.

The variables were defined as follows: (a) A-variables are life events which are great enough to effect change within the family system, (b) B-variables are the individual coping abilities of the individual family members, (c) Cvariables are the associated, subjective meanings attached to a particular event, and (d) X-variables are the outcome of family stressors, resources, and perceptions.

Double ABCX model of caregiving. Rankin (1992) reviewed the work of McCubbin and Patterson (1983) and modified their model such that the effort that the family expends to modify, via anticipation and active response, is taken into account. The modified product is the "Double ABCX" model which takes into account a feedback loop between the new level of family organization and succeeding stressors.

Circumplex model of caregiving. Rankin and others (1992), also reviewed the work of Olson, Russell, and Sprenkle (1983) and presented the "Circumplex" model which focuses on the family's present status. The two family dimensions explored are cohesion and adaptability. Rankin et al. (1992) suggested that the combination of the Double ABCX and the 
Circumplex models, with their inherent interactivity, provided the best paradigm from which to assess caregivers and their burden.

Caregiving and the wear-and-tear hypothesis. Walker, Acock, Bowman, and $\mathrm{Li}$ (1996) conducted a study in which the wear-and-tear hypothesis was tested. In its simplest form, the wear-and-tear hypothesis states that the longer care is provided, the more negative the outcome of the caregiving experience. Walker and colleagues (1996) found that while wear-and-tear is variable among caregivers, there appears to be an inverse relationship such that caregiving satisfaction declines over time in response to the increase in the amount of care given. This is supported by Hooyman, Gonyea and Montgomery (1985), and Fredman and Daly (1997) who suggested that burden has been found to be greater when more ADL help is given.

Caregiving and the adaptation hypothesis. Stephens and Zarit (1989) posited an alternative model to the wear-and-tear hypothesis entitled, "the adaptation hypothesis." These researchers suggest that caregivers are seen as acclimating to their circumstances and experience little change, and possibly, even experiencing improvement in outcomes over time. Furthermore, they suggested that if the carereceiver's health is stable, the 
caregiver is provided the opportunity to adjust to caregiving demands, thereby increasing the likelihood of the caregiver's adaptation to the situation over time (Stephens \& Zarit, 1989).

Caregiving and the model of human occupation. In proposing the theory of the Model of Human Occupation (MOHO), Kielhofner (1995) subscribes to a general systems theory of human occupation. MOHO's view reduces phenomena into units that can be independently studied, evaluated, assessed and treated. In viewing caregiving, caregiver assessment, and caregiver burden from the theoretical perspective of $\mathrm{MOHO}$, the focus is on the hierarchical interplay of the subsystems, their dynamic interaction with the environment and their adaptation and evolution over time, all of which are facilitated by the feedback loop.

MOHO's subsystems are dubbed the volition, habituation and mindbrain-body performance subsystems. The volition subsystem is composed of three aspects: (a) one's sense of personal causation and the degree of control one feels one has in directing one's life, (b) interests or those activities one enjoys performing, and (c) personal values. Habituation encompasses routine, automatic activities or habits and roles which are internalized. The mind-brain-body performance subsystem is composed of 
prerequisite skills which culminate in actions including: (a) musculoskeletal (the biomechanical aspect), (b) neurological (both central and peripheral nervous systems), (c) cardiopulmonary (cardiovascular and pulmonary systems), and (d) symbolic images (system guidance in the planning, interpretation and production of behavior). The mind-brain-body performance subsystem is governed by the volitional and habituation subsystems (Kielhofner, 1995). Skaff and Pearlin (1992) have observed that as caregivers are thrust into an additional, often unwanted role, they may feel powerless, or lacking control over their situation which would affect the volitional level (Kielhofner, 1995). Furthermore, Brody (1985) asserts that while caregiving by an adult child may be a normative expectation, it is not linked to a particular phase in the life cycle. This may further compound one's feelings of loss of control/loss of self. The caregiver's volition subsystem may also be taxed by the loss of time for interests, and a conflict in what one deems important.

The roles of caregivers may affect the volition subsystem by decreasing caregivers' sense of personal causation and their sense of their degree of control over their lives. The interests and activities which caregivers have previously enjoyed engaging in may suddenly be displaced 
by new and often, unwanted and/or unexpected activities thrust upon them via the caregiving role (Kielhofner, 1995). The values of caregivers may be challenged such that they are torn between their personal preferences of what is expected of them by their immediate family, their extended family, and their culture at large. A dissonance may result between their personal values and the values which are thrust upon them by extraneous sources.

Caregivers' habituation subsystems are affected by the unpredictability of interaction between caregivers and carereceivers (Kielhofner, 1995). Without the application of the feedback process which is inherent in $\mathrm{MOHO}$, this dissonance is likely to precipitate a tremendous amount of stress not only between caregivers and carereceivers, but also among family dynamics (Greenberg, Monson, \& Gesino, 1993).

The motor process and communication skills innate in the mindbrain-body performance system are monitored by the volitional and habituation subsystems, such that appropriate behaviors are elicited (Kielhofner, 1995). These subsystems indicate that the caregiver/carereceiver relationship cannot be viewed in isolation, but must be viewed in the greater realm of general systems theory (GST). GST views the relationship as an ongoing relationship which monitors itself, adjusts its 
output, monitors the adjusted output, and makes subsequent monitored changes such that the outcome is desirable and compatible among the three subsystems (Kielhofner, 1995; Skaff \& Pearlin, 1992). Therefore, mechanisms which will foster the functioning of the feedback loop within the dyad must be in place. Educating the caregiver, carereceiver and family members in possible changes in roles, in developing positive coping strategies, and in the identification of what mechanisms are necessary to afford satisfaction to caregivers in their roles, are crucial to facilitate functional adjustment of role changes (Greenberg et al., 1993). Therefore, when an OT is involved in the treatment of an elderly patient, the OT must also take care to assess the dynamics and interactions of the patient, the prospective caregiver, and the family within the frame of reference of MOHO. While homeostasis can be facilitated in family dynamics, the family members must possess the tools necessary for coping and for selecting functional, rather than dysfunctional, methods of achieving this equilibrium state.

\section{Assessing Caregiver Burden}

Greenberg et al. (1993) elaborate that while measures of assessing caregiver burden are available, most scale items ignore the family unit as a 
functioning whole. Furthermore, they state that the assessment instruments that are available and are widely used have been developed in research centered on families with young children. Greenberg, Monson, and Gesino (1993) enumerate two difficulties with the application of these instruments to geriatric practice: (a) many scale items are inappropriate in assessing relationships between adult children and their parents, and (b) aspects of family functioning pertinent to caring for an elderly parent/relative are not present. There are, however, several assessments available which do address the needs of caregivers of people with severe mental illness (Schene, Tessler, \& Gamache, 1994).

Global Assessment and Multidimensional Assessment

Caregiver burden assessment tools and tools which measure the functioning of carereceivers are frequently administered assessments within the clinical setting by a variety of healthcare professionals. These tools may measure burden from either (a) a global view (Zarit, Reever, \& BachPeterson, 1980) or (b) a multifactorial, or multidimensional view (Caserta, Lund, \& Wright, 1996; Novak \& Guest, 1989; Kosberg \& Cairl, 1986; Radloff, 1977). While assessments that yield a global score may include various domains such as health status, activity level and financial burden, 
the scoring is such that it represents a total, or global representation of overall burden. These measures, therefore, support the hypothesis that many aspects of caregivers' lives are affected by caregiving, however, it is impossible to determine the levels of burden experienced in each of the separate domains which they probe (Novak \& Guest, 1989). Multifactorial assessment tools, by virtue of their design, permit scores within each domain probed. By using a multifactorial assessment tool, one may isolate the extent to which caregivers are burdened by a specific domain or factor, or identify the specific areas in which carereceivers need assistance.

\section{Assessment of Burden in Spousal Caregivers}

Zarit Burden Interview. The Zarit Burden Interview (ZBI) (Zarit, Reever, \& Bach-Peterson, 1980) is an assessment of burden for spousal caregivers of persons with dementia. While the ZBI yields a global score, it will be mentioned since it is used by many clinicians and the most current assessment tools have drawn upon the ZBI to some extent. The ZBI assesses caregiver's health, psychological well-being, finances, social life, and the relationship between the caregiver and the carereceiver. It is easily administered in five to ten minutes and contains 29 questions. It can be very useful to healthcare practitioners. Of particular interest is the fact that the 
authors reveal that the number of visits by family was inversely related to caregiver burden $(r=-0.48, \mathrm{p}<0.05)$. Their conclusion is that the likelihood of an elder with dementia being institutionalized may be decreased if the primary caregiver is relieved of some of his/her feelings of burden, which in turn may lessen the breakdown in the relationship in the caregiving dyad

Screen for Caregiver Burden. Another instrument that yields a global score is the Screen for Caregiver Burden (SCB) (Vitaliano, Russo, Young, Becker, \& Maiuro, 1991). While the SCB measures both objective burden (OB) and subjective burden (SB), it lacks subscales. The SCB was designed for the population of spousal caregivers of elders with dementia. Objective burden is scored solely by the occurrence of an experience; an item occurrence score of zero represents that the experience did not occur; a score of one indicates the experience did occur. Subjective burden is scored by four anchor points: one = no occurrence or occurrence with no distress, two $=$ mild distress, three $=$ moderate distress, and four $=$ severe distress. High scores indicate the possible existence of burden. The domains assessed by the SCB include care receiver behaviors, disruptions in family and social life, and caregiver affective responses. Its twenty-five questions take less 
than ten minutes to administer. The SCB requires no special training in its administration, and it can be used by all healthcare practitioners as a screening tool. The authors report test-retest reliability of 0.70 for $\mathrm{OB}$, and 0.64 for SB ( $p<0.001$ for both); a decrease in mental status of the carereceiver was negatively correlated to both $\mathrm{OB}$ and $\mathrm{SB}$ at the $\mathrm{p}<0.05$ level of significance ( $r=-.22$ and -.24 for $\mathrm{OB}$ and $\mathrm{SB}$, respectively).

\section{Assessment of Burden in Non-Spousal Caregivers}

Caregiver Burden Inventory. The Caregiver Burden Interview (CBI) (Novak \& Guest, 1989) is a multidimensional measure of burden in nonspousal caregivers of older individuals who seem disoriented or confused.

The CBI assesses five domains: (a) time-dependent burden, (b)

developmental burden, (c) physical burden, (d) social burden, and (e) emotional burden. These five dimensions may be charted over time via repeated administrations, yielding a caregiver burden profile (CBP) which may be used to track the levels of burden in each of the five domains.

The 24 questions are scored according to either the presence or the subjective report of each situation occurring; administration time is approximately five to ten minutes. The instrument requires no special 
training to administer and the authors report that the CBI has utility for all healthcare practitioners.

Cost of Care Index. The Cost of Care Index (CCI) (Kosberg \& Cairl, 1986) is a multidimensional assessment tool for caregivers of elderly individuals who are frail or who have dementia. The CCI assesses the domains of personal and social restrictions, physical and emotional problems, economic costs, value investment in caregiving, and perception of the elder as provocateur. The 20 questions of the CCI can be administered in five to ten minutes and are scored on a four point scale for each item, from 1 = strongly disagree to $4=$ strongly agree. An increase in the score is equal to an increase in the cost of caring for the carereceiver. Kosberg and Cairl (1986) report that the CCI was developed for both case managers and clinicians. Predictor variables of the CCI include caregiver characteristics (gender, education, income, employment, relation to patient and age), caregiver formal support, caregiver informal support, caregiver functioning (psychopathology, mental health, physical health and ADL trouble), consequences of caregiving (functional troubles and intolerance), and patient functioning (cognitive, behavioral and functional impairment). These factors were identified in a conceptual model under the five domains 
of the CCI. The authors suggest that if the caregiver places a low value on aspects of caregiving, the practitioner may identify a situation where the carereceiver may not be receiving adequate care.

\section{Assessment of Burden: Caregiver of an Older Adult}

Caregiver Hassles Scale. The Caregiver Hassles Scale (Kinney \& Stephens, 1989) is a multidimensional scale designed to assess caregivers' perceptions of the daily hassles associated with their caring for an older adult. The authors state that this scale differs from other measures of burden and strain in that it probes the minor events involved in caregiving which occur throughout the day. Caregivers are asked to assess 42 items. The caregivers are to indicate which, if any, of the 42 items cause them to be annoyed or bothered. If the caregivers are not annoyed or bothered by the event, it is scored as a zero, or non-event. Novel to this scale is that it can yield either a global or a multidimensional score. The global score yields an indication of the degree to which caregivers feel "hassled," while the multidimensional scoring provides a score in each of five areas: (a) basic ADLs, (b) IADLs, (c) cognition, (d) behavior, and (e) caregiver support network. Kinney and Stephens (1989) suggest that the scale offers a general level of stress as well as the ability to identify the source(s) of that stress. 


\section{Assessment of Depression}

Center for Epidemiologic Studies Depression Scale. The Center for

Epidemiologic Studies Depression Scale (CES-D) (Radloff, 1977) is an assessment tool which yields a global score and may be administered to both caregivers and carereceivers. Radloff (1977) states that the domains assessed include: depressed affect, positive affect, somatic and retarded activity, and interpersonal domains. The 20 questions of the CES-D may be administered in five to ten minutes. The author scores each question on a scale of one to four, as follows: (a) score of $1=$ rarely or none of the time $(<$ 1 day); (b) score of 2 = some or a little of the time (1-2 days); (c) score of $3=$ occasionally or a moderate amount of time (3 - 4 days); and (d) score of $4=$ most or all of the time ( $5-7$ days). (Number of days relates to the number of days in the past week that the individual felt or behaved that way). The author states that item numbers $4,8,12$, and 16 are positively worded, and numerical values should be reversed for scoring purposes). The author explicitly states that depression can not be diagnosed via the CES-D, but that a high score is a good predictor of the possible presence of depression. The CES-D is useful for all healthcare practitioners. Internal consistency between general population and patient sample, via coefficient 
alpha and Spearman-Brown split-half method, was equal to .85 and .90 , respectively. The CES-D was positively correlated with the Lubin Scale, Bradburn Negative Affect Scale, Bradburn Balance Scale and Langner Scale, with $r=.70, .55, .72$, and .60 , respectively (Radloff, 1977).

Beck Depression Inventory. The Beck Depression Inventory (BDI) (Beck, Ward, \& Mendelson, 1961) contains questions on 21 characteristics which are associated with depression. The characteristics assessed include: (a) mood, (b) pessimism, (c) sense of failure, (d) satisfaction, (e) guilt, (f) sense of punishment, (g) disappointment in oneself, (h) self accusations, (i) self-punitive wishes, (j) crying spells, (k) irritability, (l) social withdrawal, (m) indecisiveness, (n) body image, (o) function at work, (p) sleep disturbance, (q) fatigue, (r) appetite disturbance, (s) weight loss, (t) preoccupation with health, and (u) loss of libido. While the BDI is often administered by an interviewer, it has been adapted such that it may be used as a self-administered assessment. The authors assert that a score of 21 or greater indicates severe depression, with about $75 \%$ sensitivity and specificity of $92 \%$. Furthermore, there is a shortened version of the BDI that contains 13 items and may be completed by the caregiver in five minutes or less. The questions are identical to the questions in the long 
version; however, the items are reversed such that the most negative statements are listed first (Gallo, Reichel, \& Andersen, 1995). Scores of 5 to 7 are consistent with mild depression, scores of 8 to 15 are indicative of moderate depression, and scores of 16 or more indicate severe depression.

\section{Multidimensional Caregiver Assessment Instruments}

\section{Philadelphia Geriatric Center-Multidimensional Assessment}

Instrument. The PGC-MAI of Lawton and others (1982) is a multidimensional assessment which is available in a full-length format which takes approximately 50 minutes to administer, a mid-length version requiring about 35 minutes, and a short version which takes approximately 20 minutes to administer. The IADL section is based heavily upon the OMFAQ.

In addition to gathering background data, the short-length version of the PGC-MAI assesses the domains of: (a) physical health, (b) instrumental activities of daily living, (c) personal self-maintenance activities (ADLs), (d) activities engaged in, (e) social relations, (f) morale, (g) environment, (h) experiences, and (i) income. Scales are provided for interpretation of scores. In assessing the domain of IADLs, the questions are specifically worded to ask the elders what they can do, not what they actually do. 
Wording questions in this mode compensates for activities which one can perform, but for some reason, perhaps because of either culture or gender, one does not perform, thereby yielding a greater insight into the person's abilities or level of independence.

In the shortened-length assessment of IADLs, each of the subdomains is rated as either (a) performed without help, (b) performed with some help, or (c) unable to perform. A 3-point scale is used, with a three representing independence, and a one complete dependence. The total possible score is 12 points. The full-length version probes nine areas and is similarly scored with a total possible score of 27 points. Scores are patient dependent and if the scale is administered over time, it may indicate deterioration or stability.

\section{Patient-Caregiver Functional Unit Scale. The Patient-Caregiver}

Functional Unit Scale (PCFUS) (Fredman \& Daly, 1997) contains both
ADLs and IADLs and probes the extent to which the carereceiver can perform each activity, and how helping the carereceiver to complete each task affects the caregiver. The PCFUS assesses multiple domains, but yields a global score, and is appropriate for both caregivers and carereceivers. The domains assessed include ADL and IADL performance. The PCFUS 
assesses both the ability of the carereceiver to perform ADLs and IADLs, and the ability of the caregiver to assist the carereceiver. The PCFUS requires approximately ten minutes to administer and is scored via computer program available from the authors. Fredman and Daly (1997) state that the PCFUS is useful in both clinical and research settings, and cite its usefulness to all healthcare practitioners.

A great innovation of the PCFUS is that in addition to covering basic $\mathrm{ADL}$ and IADL tasks, the PCFUS takes into account whether there is a physical, emotional, physical and emotional, or no cost to the caregiver in performing/aiding the carereceiver in the performance of the task being assessed, which in turn, permits assessment of the caregiver's ability to meet these needs.

The PCFUS has an inter-rater reliability of $r=0.98$, and test-retest reliability of $r=0.89$ (Fredman \& Daly, 1997). The authors state that scores from the instrument were significantly associated with the Burden Interview, Perceived Stress Scale, and Geriatric Depression Scale scores. $\underline{\text { Social Assessment of Caregivers }}$

Family APGAR and Friends APGAR. The Family APGAR and Friends APGAR (Smilkstein, Ashworth, \& Montano, 1982) are instruments 
which were not specifically developed to assess either caregivers or elders; however, they are used as a screening tool to assess social functioning. The authors caution that the tools must not be used in isolation, but rather, administered together. The rationale in administering both the Family APGAR and the Friends APGAR is that some individuals have more intimate social relationships with friends than with family members. Each of the APGARs contains five questions. Each positive response to a question is scored as one point, for a total possible ten points. Scores of less than three indicate a highly dysfunctional family, scores of four to six indicate moderate family dysfunction. Smilkstein and colleagues (1982) suggest using the APGARs as screening tools in the following four situations: (a) when interviewing new patients, (b) when interviewing persons who will be caring for a chronically ill family member, (c) following an adverse event, or (d) when the patient's history indicates that a dysfunctional family is itself a problem.

Resource For Caregiver Burden Assessments (Mentally III)

Schene, Tessler, and Gamache (1994) have assembled a compendium of 21 available assessment tools which measure family or caregiver burden which may be experienced while providing care for an individual 
experiencing severe mental illness. Criteria and operational definitions for inclusion in this assemblage are as follows:

Caregiving refers to the relationship between two adult individuals who are typically related through kinship. One, the caregiver assumes an unpaid and unanticipated responsibility for another, the care recipient, whose mental health problems are disabling and long-term in nature, with no curative treatment available. The care recipient is unable to fulfill the reciprocal obligations associated with normative adult relationships and the mental health problems are serious enough to require substantial amounts of care (p. 229).

Within this group of 21 assessment tools, burden was determined to be multidimensional in nature, with most researchers differentiating between objective and subjective burden, even though these concepts may be operationalized differently (Schene, Tessler, \& Gamache, 1994). Some scales were determined to be appropriate to research only: (a) Social Behavior Assessment Schedule, (b) Subjective Burden Scale, (c) Family Distress Scale, (d) Family Burden Questionnaire, (e) Family Burden Interview Schedule, (f) Family Burden and Services Questionnaire, (g) Norwegian Family Impact Questionnaire, and (h) Family Economic Burden Interview. Tools which are appropriate for both research and clinical use include: (a) Burden on Family Interview Schedule, (b) Family Distress

Scale for Depression, (c) Scale for Assessment of Family Distress, (d) 
Family Burden Scale, (e) Thresholds Parental Burden Scale, (f) Family

Members Perceptions of Enforced Psychiatric Institutionalization, (g) Texas Inventory of Grief - Mental Illness Version, (h) Significant Other Scale, (i)

Questionnaire for Family Problems, (j) Involvement Evaluation

Questionnaire, (k) Family Caregiving of Persons with Mental Illness

Survey, (1) Burden Assessment Scale, and (m) Impact of Mental Illness on

Family/Household Members. Of the assessment tools which are appropriate

to both research and clinical applications, (b), (e), (g), (h), (k), (l), and (m)

were developed in the United States. Formats of administration vary and

include self-administered questionnaire (e, g, and 1), structured personal

interview (e, h, k, l, and $\mathrm{m}$ ), semi-structured personal interview ( $\mathrm{b}$ and e),

and structured telephone interview (1) (Schene, Tessler, \& Gamache, 1994).

The authors (1994) state that the number of questions asked and the time to complete the assessments varies from nineteen questions and five minutes

(1) to 437 questions and two hours, given over four weeks' time (k).

Questionnaire as a Research Method

Data collected via questionnaire is a rapid method of gathering data.

When preparing a questionnaire, care must be taken to ensure that the questions are neither ambiguous nor unclear (Bailey, 1991). If it is 
determined that a question is ambiguous after the data are collected, the entire sample of data must be discarded unless special statistics are employed in the analysis of the results (Bailey, 1991). When formulating the questions, one must decide whether to use closed-ended questions, open-ended questions, or a combination of both. While open-ended questions provide for a much greater variety of responses, difficulties may occur in interpretation of the responses. The researcher may experience a low return rate from the mailing; the average return rate for questionnaire mailings is approximately thirty percent. Suggestions for increasing the return rate include: (a) keeping the questionnaire short - less than thirty minutes to complete; (b) designing and employing an attractive, easy to follow format; (c) preparing an interesting cover letter; (d) providing a selfaddressed stamped envelope for the return of the questionnaire; and (e) providing a specific time frame for the return of the questionnaire (Bailey, 1991). After the questionnaire is designed, it should be piloted on a small number of individuals that represent a target population. This will allow the researcher to revise the instrument such that there are no major flaws in the questionnaire; thus, increasing the validity of the instrument.

\section{Summary of the Literature}


Many adults find themselves participating in the role of caregiver to an elderly family member. It is clear from the review of the literature that a plethora of research is centered around caregiving and caregiver burden.

This research indicates that when health professionals treat elderly patients, comprehensive treatment of these elderly patients should include assessment of their caregivers as well.

Burden and the need for assessing caregivers' burden, may be framed within any of several frames of reference or theories, including the $\mathrm{ABCX}$ model, the Double ABCX model, the Circumplex model, the Adaptation hypothesis, the Wear and Tear hypothesis, Existentialism, or MOHO.

Few researchers, if any, will deny the existence of burden, but there is no consensus as to the construct and dimensions of burden. Several proposed constructs include: (a) subjective and objective burden, (b) economic burden, (c) physical burden, (d) social burden, (e) emotional burden, (f) psychological burden, and (g) life events. Researchers have investigated single constructs and multiple constructs of burden with varying results, which seems to indicate that more research is needed. Most researchers, however, agree that burden is a multidimensional concept, and as such, should be assessed via multidimensional assessment instruments. 
The manner in which individuals cope with their roles as caregivers has also been heavily researched. Again, there is no consensus, and studies often offer conflicting results. Areas of speculation have included: (a) gender of the caregivers, (b) ADL/IADL performance of carereceivers, (c) employment status of caregivers, and (d) family dynamics of both the caregiving dyads and immediate families.

The list of multidimensional instruments included in this research is not intended to be a compendium of all multidimensional instruments. Rather, they were selected because they repeatedly surfaced in the literature, and globally acknowledged experts in the field of aging tout their utility. Furthermore, ease of use and amount of time required to administer the assessment were considered by this researcher. 
Chapter III

\section{Method}

\section{Objectives and Research}

The primary objectives of this study were to examine the extent to which occupational therapists, currently giving direct delivery of services to the elderly, assess their caregivers, and to determine which assessments are used. Additional objectives were to analyze the relationships of assessments used to practice settings, therapist experience, and level of education of OTs practicing in geriatric settings.

The following research questions were asked:

Question 1: To what extent are occupational therapists who are currently employed in direct patient contact with the elderly assessing their caregivers?

Question 2: Which assessments are being used?

\section{Subjects and Setting}

The study consisted of a questionnaire (Appendix A) mailed to a random sample of 500 occupational therapists who are current members of the American Occupational Therapy Association (AOTA) and who currently subscribe to AOTA's special interest group publication in 
gerontology. Five hundred questionnaires, cover letters, and stamped, addressed return envelopes were mailed. The purpose of the survey was explained in the accompanying cover letter. The cover letter also stated that data obtained will be treated as group data, thereby ensuring the confidentiality of each respondent. Directions asked the participants to check or write in responses appropriate to the questions asked. The instrument contained two screening questions to ensure that the potential participants were currently working in aging and that they were involved in direct patient care/contact. If the potential participants answered "yes" to both of the screening questions, they were asked to continue and complete the survey. If any respondents answered "no" to either or both of the screening questions, they were asked to return the questionnaire so that the researcher would not include their names in further mailings if an acceptable return rate of $30 \%$ was not obtained. Potential participants were asked to return the questionnaire within a two-week time frame. All responses remained anonymous.

\section{Design}

The questionnaire used in this study was developed by the researcher and the committee chair. There were two screening questions in the 
questionnaire which served to ensure that the potential participants actually fit the research criteria. The survey included demographic items such as the therapists' levels of education, years in clinical practice, current employment setting, region of the country, and ethnic/racial identity. The remaining items asked for information from the therapists regarding their practices in assessing caregivers of the elderly, specifically, types of informal and formal assessment used, frequency of their use, and effects of managed care on assessment. The specific formal, multidimensional assessments included on the instrument were selected due to their frequency of use in the literature, and their popularity among both clinicians and researchers.

The surveys were mailed out and were coded such that individuals who responded would not be included if a second mailing became necessary. Responses were kept in a separate filing cabinet from the list of coded names. The list of coded names was destroyed after a minimum $30 \%$ rate of return was obtained. To ensure the anonymity of each respondent's participation, all data were treated as group data. 


\section{Data Collection Technique}

A pilot questionnaire containing 14 items was piloted with five occupational therapists practicing in aging in Dade County, Florida.

Responses and feedback obtained from the pilot testing were used to modify, clarify, and refine the questionnaire. The final questionnaire (see Appendix A) was modified by the researcher and the thesis chair based on information obtained from the pilot study.

Basic demographic data were obtained. Specifically, information regarding the number of years in OT practice, number of years practicing in aging, highest level of education attained in OT, highest level of education attained in any area, geographic location, ethnic identity, and type of facility currently employed were collected.

One question asked respondents to check off which types of informal assessment methods they used in the past and another question asked participants to identify which types of formal assessments are being used.

The next question asked participants to indicate the frequency with which they use specific multidimensional and global assessments. A Likerttype scale $(0=$ unfamiliar with the assessment/author to $5=$ always used $)$ was used to indicate frequency of use. The specific tests included within the 
list were chosen after an extensive review of the literature. Tests, which were regularly cited in the literature as being effectual in the assessment of caregivers' burden, were selected.

The final section provided for open-ended comments so that practitioners could provide feedback regarding any important issues which have been omitted, and for general comments regarding assessment.

\section{$\underline{\text { Statistical Analyses }}$}

Frequencies and percentages were calculated for all demographic, assessment and frequency variables. Types and frequencies of assessments used were compared by the therapists' highest degree in OT, highest degree in any field, type of facility where currently employed, number of years in OT, and number of years practicing in aging. Statistical tests used for these comparisons included the $\mathrm{X}^{2}$ test, t-test, one-way ANOVA, and Pearson's correlational analysis.

Limitations of the Study

Generalization of the results of this study to the total population of occupational therapists practicing in gerontology is limited for the following reasons: 
1. Since the random mailing list was generated from AOTA's registered members who are members of the gerontology special interest group who practice in gerontology, the responses obtained from this sample may not be representative of the population of all OTs who practice in gerontology.

2. The return rate may suggest a self-selection bias.

3. Validity and reliability of the questionnaire have not been established.

4. The researcher has assumed the respondents have answered the questions truthfully and accurately. 


\section{Chapter IV}

\section{$\underline{\text { Results }}$}

\section{Demographic Data}

A total of 266 (53.2\%) of all questionnaires were returned. Of these, 204 surveys (41\%) met inclusion criteria. All demographic questions were answered by all participants with the exception of one missing value in both highest degree earned and ethnic identity.

Number of years of experience. Subjects were asked to indicate both their number of years' experience in OT, and their number of years' experience working directly in aging. Total years working in OT had a range of 0.5 years to 38.0 years $(\underline{\mathrm{M}}=11.42, \underline{\mathrm{SD}}=7.32)$. Total years working directly in aging spanned a low of 0.5 years to a high of 26 years $(\underline{M}=8.06, \underline{\mathrm{SD}}=5.70)$.

Employment setting. Respondents were asked to identify their employment setting from a number of options. These options included: skilled nursing facility, hospital, retirement village, home health, extended care facility, outpatient facility, adult congregate living facility (ACLF), or other. Skilled nursing facilities $(\underline{n}=128,62.7 \%)$, hospitals $(\underline{n}=27,13.2 \%)$, and home health $(\mathrm{n}=19,9.3 \%)$ comprised the employment settings for the 
greatest number of OTs. The remaining settings represented only $14.8 \%$ of the sample and included extended care facilities ( $\underline{n}=12,5.9 \%)$, outpatient facilities $(\underline{n}=4,2 \%)$, retirement villages $(\underline{n}=1,0.5 \%)$, and "other" $(\underline{n}=11$, $5.4 \%)$

Level of education. Two questions were asked regarding the participants level of education. The first question asked was "What is the highest degree you have earned in OT?" One hundred sixty-nine respondents (82.8\%) indicated that they held a bachelor's degree in OT, while $35(17.2 \%)$ held a master's degree in occupational therapy. In response to the second question, "What is the highest degree you have earned in any field?" 45 respondents $(22.1 \%)$ indicated having earned a master's degree and three individuals $(1.5 \%)$ held a doctoral degree.

Geographic region of practice. Table 1 presents the frequencies and percentages of the geographic distribution of practitioners. The Midwest was most represented, with $27.5 \%$ of the OTs responding, while the West Coast $(1.5 \%)$ was the least represented. 
Table 1

Subject Geographic Region of Practice $(n=204)$

Region

n $\quad \%$

Midwest

56

27.5

Northeast

47

23.0

Southeast

44

21.6

Southwest

31

15.2

Northwest

16

7.8

Middle Atlantic

7

3.4

West Coast

3

1.5

Ethnic identity. Table 2 presents the frequencies and percentages of the ethnic identity of the respondents. An overwhelming majority of the respondents identified their ethnicity as white (88.6\%). Black/AfricanAmerican and multiracial respondents accounted for $3.5 \%$ and $3.4 \%$ of respondents, respectively. Asian cultures were divided into two groups: 
Filipino, Indian, or Chinese (2.5\%) and Asian American/Pacific Islander $(0.5 \%)$. Furthermore, $1.5 \%$ of respondents were Hispanic.

\section{Table 2}

Subject Ethnic Identity $(n=203)$

Ethnicity

$\underline{\mathrm{n}}$

$\%$

White

180

88.7

Multiracial

7

3.4

Black/African-American

7

3.4

Asian (Filipino, Indian, Chinese)

5

2.5

Hispanic

3

1.5

Asian American or Pacific Islander

1

0.5

Total

203

100.0

Assessment of Caregivers

Research question one asked the extent to which OTs who are currently employed in direct patient contact with the elderly assess their 
caregivers. Research question two asked which types of assessments were being used.

The questionnaire was divided into several sections. The first section asked respondents to indicate all of the five types of activities related to caregiving of the elderly in which they regularly and professionally participate. The next section asked respondents to indicate which types of formal assessments that they regularly used. A list of ten assessments that are often cited in the literature was selected. If participants did not use formal assessment instruments, they were asked to indicate that they did not use formal assessments. Respondents also had the opportunity to list any formal assessments that they used which were not on the list and to explain why they used those assessments. Finally, a section that listed four types of informal assessment of caregivers of the elderly was provided. Respondents were asked to indicate all of the types of informal assessment that they regularly used. There was a provision for participants to indicate that they do not informally assess caregivers.

Professional Caregiving Activities

One question asked respondents to indicate all of five activities related to caregiving of the elderly in which they professionally participate. 
More than $90 \%$ of respondents indicated that they provided patient and/or caregiver education and participated in discharge planning. Support group participation (13.7\%) was the activity least engaged in by clinicians. The frequencies and percentages are summarized in Table 3.

\section{Table 3}

Professional Activities Related to Caregiving

Activity

$\underline{\mathrm{n}} \quad \%$

Patient and/or caregiver education

198

97.1

Discharge planning

185

90.7

Home evaluations

175

85.8

Environmental assessments/modifications 144

70.6

Support group participation

28

13.7

\section{Formal Caregiver Assessment Tools}

There are two basic types of formal caregiver assessment: global and multidimensional. Global assessments may measure one or more domains, but yield a single score. This does not allow the evaluator to pinpoint which 
domain may be troublesome to the caregiver. Conversely, multidimensional caregiver assessment includes more than one domain or dimension, and yields a separate score for each of the domains. Both global and multidimensional assessments may be found in the literature. Furthermore, either type of these assessments are often assembled by "borrowing" sections of existing assessments, or facilities may create assessments which they feel better address the needs of the populations that they serve.

Research question one served to determine the extent to which OTs practicing in aging assessed the caregivers of their elders. Since the literature revealed that there are no universally accepted tools that OTs use for assessment of caregivers of the elderly, respondents were asked to identify the types of assessments that they used. Participants were also asked to indicate if they had never performed formal caregiver assessment. Of the 204 respondents, 67 subjects (32.8\%) indicated that they formally assess caregivers of their elderly patients, while 137 subjects $(67.2 \%)$ indicated that they do not perform formal caregiver assessment.

Research question two asked which formal caregiver assessments they used in their practice (Table 4). The formal assessment tool most commonly used was a facility created assessment $(\underline{n}=51,25 \%)$, while $8.3 \%$ 
$(\underline{n}=17)$ of all respondents used sections of existing assessments.

Multidimensional, global and "other" assessments were used by less than $4 \%$ of the respondents.

Table 4

Formal Caregiver Assessment Methods

Assessment

$\underline{\mathrm{n}}$

$\%$

Formal assessment is not performed

137

67.2

Facility created assessment

51

25.0

Assessments created by using sections of

existing assessments

17

8.3

Global assessments

8

3.9

Multidimensional assessments

6

Other

5

2.5

Therapist Rationales For Not Using Formal Caregiver Assessment

Respondents were asked to identify their rationales for not formally assessing the caregivers of their patients. Several themes evolved from the 
131 subjects who responded (Table 5). The three most frequently cited rationales were: they were not familiar with available formal assessments for caregivers $(\underline{n}=29)$, their facility does not have these instruments ( $\underline{n}=$ $28)$, or reliance on informal methods of assessment ( $\underline{n}=27)$. If "lack of time"

$(\mathrm{n}=16)$ and "focus is on the patient" $(\mathrm{n}=10)$ are combined as "restraints related to intervention with patient," this would be another major reason for not utilizing formal caregiver assessments. 
Table 5

Therapist Rationales For Not Using Formal Caregiver Assessment $(n=131)$

Rationale

Unfamiliar with formal assessment/tools

No tool available at facility

Reliance on informal methods of assessment

Lack of time

Caregiver education

Focus is on patient (secondary to

reimbursement issues)

Professional staff are caregivers of patient

Lack of contact with caregiver

Assessment viewed as intrusive by caregiver(s) 6

Preference for informal methods

Patients discharged to residential facilities
29

28

27

16

11

8.4 


\section{Multidimensional Caregiver Assessments}

A careful review of the literature of formal, multidimensional caregiver assessment tools yielded several instruments that were repeatedly cited as important in assessing the caregiver-carereceiver dyad. Ten of these assessments were selected for inclusion in the research questionnaire.

The ten instruments included in the questionnaire were: (a) Family

APGAR, (b) Friends APGAR, (c) Zarit Burden Interview (ZBI),

(d) Caregiver Burden Inventory (CBI), (e) Cost of Care Index (CCI), (f)

Patient-Caregiver Functional Unit Status (PC-FUS), (g) Screen for

Caregiver Burden (SCB), (h) Center for Epidemiological Studies

Depression Scale (CES-D), (i) Beck Depression Inventory (BDI), and (j)

Caregiver Hassles Scale (CHS). Subjects were asked to indicate their usage of each instrument on a six-point Likert scale. One choice allowed the respondents to indicate that they were unfamiliar with the author/assessment. The remaining five choices were used to assess the frequency of use of each of the ten listed assessments. The choices were: "never use," "seldom use," "occasionally use," "frequently use," and "always use" the particular assessment. Of the 204 subjects, six participants 
did not respond as to the use of the Friends APGAR, while five participants did not respond to the use of any of the remaining nine formal assessments. Familiarity With Ten Formal Multidimensional Assessment Tools More than $94 \%$ of respondents stated that they were either "unfamiliar with the author/assessment," or "never use the assessment," for nine of the ten formal assessments presented. The one exception was the Beck Depression Inventory, with only $75 \%$ of the respondents citing they were unfamiliar with the author/assessment or never used it. The Cost of Care Index, the Caregiver Burden Inventory, and the Patient-Caregiver Functional Use Status were the only assessments which were reported as being used "frequently," by two and one participants, respectively.

Family APGAR. The Family APGAR was reported as being used occasionally by one respondent, seldom used by two respondents, and never used by 43 respondents. One hundred fifty-four (75.5\%) were unfamiliar with the assessment/author. Five participants did not respond.

Friends APGAR. The Friends APGAR was reported as being used occasionally by one subject, and seldom used by one subject. Thirty-nine respondents never used this assessment and 157 respondents cited being 
unfamiliar with the assessment/author. Six participants did not respond to the question.

Zarit Burden Interview. One individual reported using the Zarit Burden Interview occasionally. No participants reported that they seldom used this instrument. Forty respondents never used the assessment while 158 were unfamiliar with the assessment/author. Five individuals did not respond.

Caregiver Burden Interview. The Caregiver Burden Interview was cited as being frequently used by two individuals. One respondent cited occasionally using the $\mathrm{CBI}$ and one cited seldom using this instrument. Forty-eight individuals never used the assessment, and 147 respondents were unfamiliar with the assessment/author. Five individuals did not respond.

Cost of Care Index. Two participants reported using the Cost of Care Index frequently and two reported using it occasionally. Three respondents seldom used the instrument, 44 never used it, and 148 respondents were unfamiliar with the assessment/author. Five individuals did not respond to the question. 
Functional Use Status was reported as being used frequently by one individual. Two respondents occasionally used this assessment tool, and three participants used it seldom. Thirty-seven respondents never used the Patient-Caregiver Functional Use Status and 156 reported being unfamiliar with the assessment/author. Five individuals did not respond.

Screen for Caregiver Burden. The Screen for Caregiver Burden was reported as being used occasionally by three participants. Two respondents cited using the instrument seldom, while 39 participants never used it, and 155 respondents reported unfamiliarity with the assessment/author. Five individuals did not respond.

Beck Depression Inventory. The Beck Depression Inventory was used occasionally by more respondents $(n=6)$ than any of the other nine instruments. Eleven participants seldom used this assessment, 39 never used the Beck Depression Inventory, and 155 respondents were unfamiliar with the assessment/author. Five individuals did not respond to this question.

\section{Center for Epidemiological Studies Depression Scale. One}

respondent reported using the Center for Epidemiological Studies

Depression Scale occasionally. Two participants seldom used this 
assessment, 45 never used it, and 151 respondents were unfamiliar with the assessment/author. Five individuals did not respond.

Caregivers Hassles Scale. The Caregivers Hassles Scale was reported as being used occasionally by one participant. Thirty-eight respondents never used this assessment, and 160 participants were unfamiliar with the assessment/author. Five individuals did not respond. (See Table 6.) 
Table 6

Frequency of Use of Multidimensional Caregiver Assessments

Variable

$\underline{\mathrm{n}}$

$\%$

Family APGAR

Unfamiliar with assessment/author

154

75.5

Never use assessment

42

20.5

Seldom use assessment

Occasionally use assessment

2

1.0

Frequently use assessment

1

0.5

Always use assessment

0

0.0

No response

0

0.0

5

2.5

Friends APGAR

Unfamiliar with assessment/author

Never use assessment

Seldom use assessment

Occasionally use assessment

Frequently use assessment

0

0.0

Always use assessment

0

0.0

No response 
Table 6 (continued)

Frequency of Use of Multidimensional Caregiver Assessments

Variable

$\underline{\mathrm{n}}$

$\%$

Zarit Burden Interview

Unfamiliar with assessment/author 158

77.5

Never use assessment

40

19.5

Seldom use assessment

0

0.0

Occasionally use assessment

Frequently use assessment

0

0.0

Always use assessment

0

0.0

No response

5

2.5

Caregiver Burden Interview

Unfamiliar with assessment/author

Never use assessment

Seldom use assessment

Occasionally use assessment

Frequently use assessment

Always use assessment

$1 \quad 0.5$

No response

$0 \quad 0.0$


Table 6 (continued)

Frequency of Use of Multidimensional Caregiver Assessment

Variable

$\underline{n}$

$\%$

Cost of Care Index

Unfamiliar with assessment/author

148

72.5

Never use assessment

44

21.5

Seldom use assessment

Occasionally use assessment

Frequently use assessment

2

1.0

Always use assessment

0

0.0

No response

Patient-Caregiver Functional Use Status

Unfamiliar with assessment/author

Never use assessment

Seldom use assessment

Occasionally use assessment

Frequently use assessment

Always use assessment

No response
156
76.5

18.0

1.5

1.0

0.5

0.0

2.5 
Table 6 (continued)

Frequency of Use of Multidimensional Caregiver Assessment

Variable

$\underline{\mathrm{n}}$

$\%$

Screen for Caregiver Burden

Unfamiliar with assessment/author

Never use assessment

Seldom use assessment

Occasionally use assessment

Frequently use assessment

Always use assessment

No response

Beck Depression Inventory

Unfamiliar with assessment/author

106

Seldom use assessment

Occasionally use assessment

Frequently use assessment

Always use assessment

No response
75

11

6

52.0

36.8

5.4

2.8

0.5

0.0

0

2.5 
Table 6 (continued)

Frequency of Use of Multidimensional Caregiver Assessment

Variable

$\underline{n}$

$\%$

Center for Epidemiological Studies

Depression Scale

Unfamiliar with assessment/author 151

74.0

Never use assessment

45

22.0

Seldom use assessment

Occasionally use assessment

2

1.0

Frequently use assessment

Always use assessment

No response

$\begin{array}{ll}0 & 0.0\end{array}$

00

5

2.5

Caregivers Hassles Scale

Unfamiliar with assessment/author

Never use assessment

Occasionally use assessment

Frequently use assessment

Always use assessment

No response
160

38

1

0

0

5
78.4

18.6

0.5

0.0

0.0

2.5 


\section{Informal Methods of Assessment}

In question number nine, participants were asked to check all of the four informal methods of assessing caregivers that they used in practice, or if they used no informal assessments. Direct questioning/discussion with the caregiver was the most frequently used method (used by all but one respondent), followed by observation (93.6\%), and information from other professionals (88.2\%). Twenty respondents checked "other" methods $(9.8 \%)$ and two indicated that they used no informal caregiver assessments. Data are summarized in Table 7. 


\section{Table 7}

Informal Caregiver Assessment Methods
Assessment Method
$\underline{n}$
$\%$

Direct questioning/discussion with caregiver

203

99.5

Observation of the caregiver

191

93.6

Information from other professionals

180

88.2

Checklists

155

76.0

Other methods

20

9.8

No informal caregiver assessment used

2

1.0

Clinical Experience, Education, and Employment Setting

Crosstabulations, Pearson correlations, and t-tests were performed to determine whether any significant relationships existed between caregiver assessment and the parameters of clinical experience, education, and employment setting.

Clinical experience and level of education. In order to determine if a relationship existed between the number of years of clinical experience in 
any area in OT by level of OT degree and by highest degree in any field, Pearson correlations and t-tests were performed. The relationship between number of years in aging and highest degree in both OT and in any area was also examined. It was found that the difference between subjects having bachelor's degrees and master's degrees in OT on total years in OT, $\mathfrak{t}(202)=$ $1.88, \mathrm{p}=.061$ was in the expected direction, although not significant at $\mathrm{p}<.05$. Occupational therapists with bachelor's degrees had a greater mean number of years experience $(\underline{\mathrm{M}}=11.86, \underline{\mathrm{SD}}=7.54)$, than OTs with a master's degree $(\underline{M}=9.31, \underline{S D}=5.78)$. No differences were found between subjects with either a bachelor's or a master's degree in OT on the number of years in aging. The data are summarized in Table 8. 
Table 8

Number of Years in Practice by Highest Degree in OT

Variables

$\underline{\mathrm{n}} \quad \underline{\mathrm{M}}$

$\underline{\mathrm{SD}}$

$\underline{\mathrm{t}}$

p-value

Total Years in OT

$\begin{array}{lrrrrr}\text { Bachelor's Degree } & 169 & 11.86 & 7.54 & 1.88 & .061 \\ \text { Master's Degree } & 35 & 9.31 & 5.80 & & \end{array}$

Total Years in Aging

$\begin{array}{lrrrrr}\text { Bachelor's Degree } & 169 & 8.34 & 5.85 & 1.55 & .123 \\ \text { Master's Degree } & 35 & 6.71 & 4.73 & & \end{array}$

There was not a significant difference $(\mathfrak{p}<.05$ level) between participants with bachelor's degrees and participants with master's/doctoral degrees in any field, on total years in aging, $\mathrm{t}(201)=1.78, \mathrm{p}=.077$. Furthermore, there was no significant difference $(p=.248)$ between respondents with bachelor's degrees and respondents with master's/doctoral degrees in any field, on total years in OT (Table 9). 
Table 9

Number of Years in Practice by Highest Degree in Any Field

Variables

$\underline{\mathrm{M}}$

$\underline{S D} \quad \underline{t}$

p-value

Total Years in OT

$\begin{array}{lrrrrr}\text { Bachelor's Degree } & 155 & 11.76 & 7.72 & 1.16 & .248 \\ \begin{array}{l}\text { Master's Degree } \\ \text { or PhD. }\end{array} & 48 & 10.35 & 5.86 & & \end{array}$

Total Years in Aging

$\begin{array}{lccccc}\text { Bachelor's Degree } & 155 & 8.47 & 5.87 & 1.78 & .077 \\ \begin{array}{l}\text { Master's Degree } \\ \text { or PhD. }\end{array} & 48 & 6.81 & 4.96 & & \\ \end{array}$

Employment Setting and Type of Caregiver Assessment

Formal caregiver assessment and employment setting. Each choice of type of formal caregiving was analyzed for possible relationship with type of employment setting. The types of formal assessment included: global assessments, multidimensional assessments, assessments created by using 
sections of existing assessments, facility created assessments and "other" assessments. More than $75 \%$ of respondents worked in either a hospital or skilled nursing facility (SNF). As such, Chi-square analyses were performed by collapsing "hospital" and "SNF" into a group called "skilled," $(\underline{n}=152)$. All remaining employment settings were collapsed into a group called "other." There was no significant relationship between any pair of variables. Informal caregiver assessment and employment setting. Each choice of informal caregiving assessment, observation of caregiver, direct questioning, information from other professionals, checklists and "other" were analyzed for possible relationships with type of employment setting. Again, since more than $75 \%$ of respondents $(\underline{n}=155)$ worked in either a hospital or a skilled nursing facility, these two settings were collapsed into a group called "skilled," which was compared to the all "other" settings combined. There was no significant relationship between any pair of variables using the Chi-square test.

Level of Education and Type of Caregiver Assessment

Level of education and formal assessment of caregivers. The subjects' levels of education both in occupational therapy and in any field were 
examined along with the ten formal multidimensional caregiver assessment tools.

The frequency data, as presented previously in Table 7, demonstrated that a large number of therapists were either unfamiliar with the assessment/author, or never used the assessment. Therefore, when performing the statistical analyses, the six possible responses were collapsed into three categories: (a) unfamiliar with assessment/author, (b) never use the assessment, and (c) seldom to always use the assessment.

\section{Level of Education and Formal Caregiver Assessment}

Highest degree in occupational therapy and formal assessment of

caregivers. Crosstabulations and Chi-Square tests were performed between therapists with the highest degree in OT (bachelor's or master's degree) and use of each of the ten formal caregiving assessments. No significant relationships at the $p<.05$ level were found between level of education and use of formal assessments.

\section{Highest degree earned and formal assessment of caregivers. When} comparing the highest degree earned in any field along with use of each of the ten formal caregiving assessments, two relationships were found to be in the expected direction, although not significant at the $\mathrm{p}<.05$ level. 
The relationship between highest degree earned and the PC-FUS

demonstrated that $83 \%$ of subjects who held advanced degrees were unfamiliar with the instrument/author, while only $77 \%$ of subjects with a bachelor's degree were unfamiliar with the instrument/author, $X^{2}(2)=4.69$, $\mathrm{p}=.096$. The second relationship appeared with the Beck Depression Inventory. There was a difference in usage of the BDI by highest degree, $\mathrm{X}^{2}(2)=5.08, \mathrm{p}=.079$. Only $44 \%$ of those subjects with advanced degrees $(n=48)$ were unfamiliar with the BDI, while $56 \%$ of subjects with a bachelor's degree $(\underline{n}=150)$ were unfamiliar with the assessment. Seventeen percent of the subjects with advanced degrees used the BDI at least "seldom," in comparison with $6.7 \%$ of those with a bachelor's degree. Education and Formal Assessment of Caregivers in the Skilled Practice Setting

The majority of subjects reported working in either a skilled nursing facility $(\underline{n}=128,62.7 \%)$ or a hospital setting $(\underline{n}=27,13.2 \%)$. As mentioned previously, these two groups were collapsed into a group called "skilled" and the remaining employment settings were grouped as "other" for statistical analyses. 
Highest degree in occupational therapy, and formal caregiver

assessment in the skilled practice setting. Since most therapists in this sample work in a skilled nursing facility, it was important to test relationships between formal assessment and highest degree in occupational therapy within this setting. Chi-Square tests between highest degree in occupational therapy and formal caregiver assessment within skilled nursing facilities showed no significant findings at the $\mathfrak{p}<.05$ level.

Highest degree in any field and formal caregiver assessment in skilled practice setting. Significance was found when the Beck Depression Inventory was compared in the skilled practice setting between educational levels, $\mathrm{X}^{2}(2)=7.20, \mathrm{p}=.027$. A smaller percentage $(42.9 \%)$ of clinicians with advanced degrees were unfamiliar with the BDI, as compared to $61.2 \%$ of subjects with a bachelor's degree. Use of BDI, seldom to always, was greater in the group with advanced degrees in any field $(\underline{\mathrm{n}}=5,17.9 \%)$ than in the group holding bachelor's degrees ( $\mathrm{n}=4,4.1 \%$ ) (Table 10). 
Table 10

Use of the BDI in Skilled Nursing Facilities and Hospitals By

Highest Degree in Any Field $(n=126)$

Use of BDI

Bachelor's Degree

Advanced Degree

$\underline{\mathrm{n}}$

$\%$

$\underline{n}$

$\%$

unfamiliar

60

61.2

12

42.9

never use

34

34.7

11

39.3

seldom to always use

4

4.1

5

17.9

Education. Employment Setting, Years of Experience, and Informal

\section{$\underline{\text { Assessment }}$}

When relating types of informal assessments to demographic variables (educational level, employment setting and years experience in either occupational therapy or aging), the relationship between total years experience in OT and the use of a checklist as part of the informal assessment of a caregiver was significant, $\underline{r}=.135, \underline{p}=.054$. The relationship between total years experience and the use of observation of the caregiver was in the expected direction, $\underline{r}=.119, \underline{p}=.088$. These two 
findings suggest that therapists with more years experience in OT are more likely to use checklists and observation as informal assessments (Table 11).

Table 11

Correlations of Use of Type of Informal Assessment By Number of Years of Experience in Occupational Therapy $(n=204)$

Use of Type of Informal Assessment

r p-value

Observation of caregiver

.119

.088

Direction questioning

$.028 \quad .690$

Information from other professionals

$.025 \quad .724$

Checklist

.135

.054

Other

.073

.303

Employment Setting, Total Years in Occupational Therapy, and Total Years in Aging $(n=204)$

One way analysis of variance was performed among employment settings: skilled nursing facility, hospital, home health, retirement village, extended care facility, outpatient facility, adult congregate living facility, 
and "all others combined," on the number of years in OT and the number of years in aging (Table 12). The difference in mean total years in aging by employment setting was not significant, $\underline{F}(3,200)=2.50, \underline{p}=.061$. Home health had the greatest number of years in aging $(\underline{M}=10.74)$, followed by "other" with a mean of 9.15 years, hospitals $(\underline{M}=8.33)$, and finally, skilled nursing facilities $(\underline{M}=7.35)$.

Table 12

Total Years in Aging by Employment Setting

\begin{tabular}{lccccc} 
Setting & $\underline{\mathrm{n}}$ & $\underline{\mathrm{M}}$ & $\underline{\mathrm{SD}}$ & $\underline{\mathrm{F}}$ & $\mathrm{p}$-value \\
\hline Skilled & 128 & 7.35 & 5.22 & 2.50 & .060 \\
Hospital & 27 & 8.33 & 5.50 & & \\
Home Health & 19 & 10.74 & 5.89 & & \\
Other & 30 & 9.15 & 7.14 & &
\end{tabular}

Issues Important to Clinicians

The final section of the questionnaire provided subjects the opportunity to make comments about any issues that they deemed relevant 
and/or important. Sixty-three participants responded. Several themes emerged, and they are presented in Table 13. 
Table 13

Issues and Changes in Clinical Practice $(n=63)$

Issue

$\underline{\mathrm{n}} \quad \%$

Difficulties in dealing with HMO's

9

12.5

Increase in time spent in pt./caregiver education

7

9.7

Decrease in quality of care

6

8.3

Increase in COTA's and techs treating patients

6

8.3

Decrease in cases referred to OT

6

8.3

Decrease in allowable treatment visits

6

8.3

Decrease in reimbursable services, i.e. home evals.

6

8.3

Inappropriate decreases in treatment

5

6.9

Time spent counseling patients/caregivers

on insurance issues and reimbursement

5

6.9

Decreases in reimbursement for home equipment

4

5.6

Decrease in caregiver involvement in therapy 


\section{Chapter V}

\section{Discussion}

In the review of the literature, the importance of the assessment of caregiver burden is indisputable (Corradetti \& Hills, 1998; Hills, 1997;

Keady, 1996; Marchi-Jones, Murphy, \& Rousseau, 1996; Levesque, Cossette, \& Laurin, 1995; Rankin, Haut, \& Keefover, 1992). Paramount to this assessment is the research community's advocacy for formal, multidimensional assessment of the caregiver within the caregiving dyad (Caserta, Lund, \& Wright, 1996; Greenberg, Monson, \& Gesino, 1993; Vitaliano, Russo, Young, Becker, \& Maiuro, 1991; Kosberg, Cairl, \& Keller, 1990; Novak, \& Guest, 1989; Kosberg, \& Cairl, 1986). The focus of this research was to determine: (a) the role of OT in relation to caregiving, including the extent that occupational therapists delivering direct patient care to the elderly assess the patient's caregiver, and (b) which assessments are used to evaluate caregivers. Several findings were noteworthy including the fact that virtually all clinicians are highly engaged in a number of professional activities related to caregiving and that presently, most activities related to caregiver assessment involve informal methods. 


\section{Professional Caregiving Activities}

A very large proportion of the sample population reported they were involved in professional caregiving activities. Virtually all (97.1\%) participants in the sample population indicated that they are regularly engaged in at least one aspect of patient and/or caregiver education, and most respondents regularly engage in four of the five professional activities associated with caregiving (patient/caregiver education, discharge planning with families, home evaluations, environmental assessment/modification, and support group participation). Essentially all therapists (97.1\%) have provided patient/caregiver education which may be explained by the fact that patient and caregiver education is generally recognized by managed care organizations as a reimbursable service. Discharge planning with families and home evaluations were cited as activities regularly performed by $90.7 \%$ and $85.8 \%$ of respondents, respectively. Slightly less than $75 \%$ of the participants were involved in environmental assessments/home modifications, while $13.7 \%$ of respondents cited they participated in family support groups. The limited number of therapists participating in support groups may be explained by the involvement of other professionals in this domain, such as social workers, case managers, and nursing practitioners. 


\section{Caregiver Assessment}

Research question one asked "to what extent are occupational therapists who are currently employed in direct patient contact with the elderly assessing their caregivers?" Research question two asked "which assessments are being used?" It was found that all except one of the 204 subjects indicated that they regularly engaged in the practice of informally assessing the caregivers of their elderly patients. The most frequently cited methods of informal caregiver assessment were direct questioning/discussion with the caregiver $(n=203)$, followed by observation $(n=191)$, checklists $(n=155)$, information from other professionals $(n=180)$, and "other" $(n=20)$.

Approximately one-third of the study participants used some form of formal assessment. The type of formal assessment most frequently cited as being used was a non-standardized assessment developed by facility personnel. When given the opportunity to cite rationales for not using formal caregiver assessments, almost $25 \%$ of the respondents indicated that there were no formal assessment tools available at their facility or that they relied on informal assessment methods. 


\section{Formal Multidimensional Caregiver Assessment}

While nearly one-third of the subjects in this study engaged in formal assessment of the caregivers of their elderly patients, most respondents were either "unfamiliar with" $(\underline{M}=118.1)$, or "never use" $(\underline{M}=41.7)$, the ten multidimensional caregiver assessments included in this research. It may be that some of the respondents who checked "never use the assessment" were hesitant to indicate they were "unfamiliar with the assessment/author" and may therefore have indicated that they "never use the assessment." Of the 10 instruments included, the Beck Depression Inventory was the instrument that was recognized by the largest number of therapists. Greater familiarity with the Beck Depression Inventory may be due to the fact that unlike some of the other instruments, it is not just a caregiver instrument but is often used with patients and therefore may have been a part of the OTs academic training. This, along with participants' previous citations that assessment tools were not available at their facilities, seems to indicate that therapists need to be educated in the availability, ease of use, and the utility of these instruments. 


\section{Educational Level and Climical Experience of the Sample Population}

In the sample population, clinicians with a bachelor's degree in OT had a greater mean number of years of experience in any field in OT compared to those with a master's degree in OT. When considering those therapists who are practicing in aging, there is still a greater number of years experience within the group holding bachelor's degrees, although the difference is not significant. Therapists with only a bachelor's degree had greater clinical experience than those therapists with an advanced degree in any field including OT. The higher percentage of therapists with longer clinical experience with bachelor's degrees may be explained by the fact that there were fewer master's degree programs in OT available in earlier years.

\section{Employment Setting and Caregiver Assessment}

When each type of formal assessment (global assessment, multidimensional assessment, assessments created by using sections of existing assessments, facility assessments, and "other" assessments) was paired with each type of employment setting, "skilled" or "other," no significant differences were found between any pair of variables. Moreover, there were no significant differences between each of the six types of 
informal assessments (observation of caregiver, direct questioning, information from other professionals, checklists, and "other" methods), and employment setting. This suggests that there is no difference in type of informal assessment practiced according to employment setting.

\section{The Beck Depression Inventory}

While there were no significant relationship between an advanced degree in OT and use of formal caregiver assessment, there was a trend found with the Beck Depression Inventory, where individuals with advanced degrees in any field were more familiar with the instrument than were individuals with bachelor's degrees.

\section{Education, Employment Setting, Years of Experience, and Caregiver}

\section{Assessment}

When considering education, employment setting, and years of experience in either occupational therapy or in aging, informal caregiver assessment via checklist was a significant part of the therapists' assessment procedure. Therapists with a greater number of years of experience in OT (regardless of number of years in aging) were more likely to use both checklists and observation. However, this was not significant but in the expected direction. Perhaps this inclination to include more than one 
caregiver assessment measure is explained by the therapists' experiential knowledge base regarding knowing more about the patient and their use of clinical reasoning which makes them more comfortable using a variety of assessment strategies.

\section{Therapist Issues}

Therapists frequently cited lack of knowledge of the existence of formal assessment tools and the lack of formal assessment tools in the clinic as the reason why formal, multidimensional assessment is not performed. Many rely on their experience and clinical expertise via observation, interview and direct questioning of the caregivers as their own form of screening for possible caregiving problems. A large portion of the sample $(62.7 \%)$ were employed in skilled nursing facilities. It may be that in these settings, there may be fewer family caregivers present or available and various healthcare workers may assume the role of formal caregivers. This may have reduced the frequency of the use of formal multidimensional assessment in the sample.

Lack of time, the pressure to produce reimbursable units and difficulty in getting caregivers to attend therapy sessions were all cited by respondents as obstacles to formal caregiver assessment. 
$\underline{\text { Recommendations }}$

It is apparent that the clinicians in this sample are relying heavily on their skills of observation to assess the caregivers of their elderly patients. Healthcare professionals are increasingly under pressure because of the reduced time for reimbursable treatment. From this survey, OTs recognize this and they are working with the families of the elderly within the domain of informal assessment. It may be that informal assessment more closely fits these constraints. From the results of this survey, it seems that caregiving assessment and intervention strategies need to be disseminated to the occupational therapy community.

In order to foster the shift from informal and global assessment to formal multidimensional assessment, the OT community needs to be educated regarding existing caregiving instruments from the non-OT literature (Corradetti \& Hills, 1998). They need to see that these assessment tools are often short and simple to administer, and may be completed independently by the caregivers. Clinicians need to become aware that these assessments can provide either different or better information than they can obtain via informal assessment. Finally, continued research on the role and presence of caregiver assessment by occupational therapists is needed. 


\section{$\underline{\text { References }}$}

Bailey, D.M. (1991). Research for the health professional: A practical guide. Philadelphia: F.A. Davis.

Baumgarten, M., Hanley, J.A., Infante-Rivard, C., Battista, R.N., Becker, R., \& Gauthier, S. (1994). Health of family members caring for elderly persons with dementia: A longitudinal study. Annals of Internal Medicine, 120 (2), 126-32.

Bergman-Evans, B. (1994). A health profile of spousal Alzheimer's caregivers: Depression and physical health characteristics. Journal of Psychosocial Nursing and Mental Health Service, 32 (9), 25-30.

Boaz, R.F., \& Muller, C.F. (1994). Predicting the risk of permanent nursing home residence: The role of community help as indicated by family helpers and prior living arrangements. Health Service Resources, 29 (4), 391-414.

Brody, E. M. (1985). Parent care as a normative family stress. Gerontologist, 25 (1), 19-29.

Brown, G.W., \& Rutter, M. (1966). The measurement of family activities and relationships. Human Relationships, 19, 239-263.

Burgener, S.C., Jirovec, M., Murrell, L., \& Barton, D. (1992). Caregiver and environmental variables related to difficult behaviors in institutionalized, demented elderly persons. Journal of Gerontology, 47 (4), 242-249.

Carlson, M., Fanchiang, S., Zemke, R., \& Clark, F. 1996). A meta-analysis of the effectiveness of occupational therapy for older persons. American Journal of Occupational Therapy, 50 (2), 89-98.

Caserta, M.S., Lund, D.A., \& Wright, S.D. (1996). Exploring the caregiver burden inventory (cbi): Further evidence for a multidimensional view of burden. International Journal of Aging and 
Human Development, 43 (1), 21-34.

Clair, J.M., Fitzpatrick, K.M., \& La Gory, M.E. (1995). The impact of psychosocial resources on caregiver burden and depression: Sociological variations on a gerontological theme. Sociological Perspectives, 38 (2), 195-215.

Corradetti, E.V., \& Hills, G.A. (1998). Assessing and supporting caregivers of the elderly. Topics in Geriatric Rehabilitation, 14 (1), 12-35.

Deimling, G. T. (1994). Caregiver functioning. In M. P. Lawton \& J. A. Teresi (Eds.), Annual review of gerontology and geriatrics (pp. 257-71). New York: Springer.

Deimling, G.T., \& Bass, D.M. (1986). Symptoms of mental impairment among elderly adults and their effects on family caregivers. Journal of Gerontology, 41, 778-784.

Farran, C. J. (1997). Theoretical perspectives concerning positive aspects of caring for elderly persons with dementia: Stress/Adaptation and existentialism. Gerontologist, 37 (2), 250-256.

Fredman, L., \& Daly, M. (in press). Methods to enhance practitioners' abilities to recognize and treat caregiver physical and mental consequences of caregiving. Topics in Geriatric Rehabilitation.

Freedman, V.A., Berkman, L.F., Rapp, S.R., \& Otsfeld, A.M. (1994). Family networks: Predictors of nursing home entry. American Journal of Public Health, 84 (5), 843-5.

Given, B.A., Given, C.W., Helms, E., Stommel, M., \& DeVoss, D.N. (1997). Determinants of family caregiver reaction: New and recurrent cancer. Cancer Practitioner, 5 (1), 17-24.

Grad, J., \& Sainsbury, P. (1968). The effects that patients have on their family in a community care and control psychiatric service - a two year follow-up. British Journal of Psychiatry, 114, 265-278. 
Greenberg, J.R., Monson, T., \& Gesino, J. (1993). Development of university of Wisconsin family assessment caregiver scale: A new measure to assess families caring for a frail elderly member. Journal of Gerontological Social Work, 12 (3/4), 49-67.

Hawkins, B. (1996). Daughters and caregiving: Taking care of our own. American Association of Occupational Health Nurses Journal, 44 (9), 433-7.

Hill, R. (1958). Generic features of families under stress. Social Casework, 39, 139-150.

Hills, G. A. (1997). Assessment of caregivers and elders. In J. Van Deusen \& D. Brunt (Eds.), Assessment in Occupational Therapy and Physical Therapy (pp. 401-417). Philadelphia: W. B. Saunders.

Hopkins, H.L. (1993). An introduction to occupational therapy. In H. Hopkins \& H. Smith (Eds.), Willard and Spackman's occupational therapy (8th ed., pp. 3-4). Philadelphia: J.B. Lippincott.

Hooyman, N., Gonyea, J., \& Montgomery, R. (1985). The impact of in-home services termination on family caregivers. Gerontologist. 23 (1), 141-145.

Keady, J. (1996). Behavioural and instrumental stressors in dementia: Refocusing the assessment of caregiver need in dementia. Journal of Psychiatric and Mental Health Nursing, 3 (3), 162-72.

Kramer, B. J. (1997). Gain in the caregiving experience: Where are we? what next? Gerontologist, 37 (2), 218-232.

Kielhofner, G. (1995). A model of human occupation: Theory and application (2nd ed.). Philadelphia: Williams \& Wilkins.

Kinney, J.M., \& Stephens, M.A.P. (1989). Caregiving hassles scale: Assessing the daily hassles of caring for a family member with dementia. 
Gerontologist, 29 (2), 328-332.

Kosberg, J. I., \& Cairl, R. E. (1986). The cost of care index: A case management tool for screening informal care providers.

Gerontologist, 26 (3), 273-278.

Kosberg, J. I., Cairl, R. E., \& Keller, D. M. (1990). Components of burden: Interventive implications. Gerontologist, 30 (2), 236-243.

Levesque, L., Cossette, S., \& Laurin, L. (1995). A multidimensional examination of the psychological and social wellbeing of caregivers of a demented relative. Research on Aging, 17 (3), 332-360.

Malone-Beach, E.E. (1995). Dimensions of social support and social conflict as predictors of caregiver depression. International Psychogeriatrics, 7 (1), 25-38.

Marchi-Jones, S., Murphy, J.F., \& Rousseau, P. (1996). Caring for the caregivers. Journal of Gerontological Nursing, 22 (8), 7-13.

McCallum, J., Mackinnon, A., Simons, L., \& Simons, J. (1995). Measurement properties of the center for epidemiological studies depression scale: An Australian community study of aged persons. Journal of Gerontology: Social Sciences, 50B (3), S182-S189.

McCubbin, H.I., \& Patterson, J. (1983). Family transitions: Adaptation to stress. In H.I. McCubbin \& D. Figley (Eds.), Stress and the family. Volume 1: Coping with normative transitions (pp 272-80). New York: Brunner/Mazel.

Miller, B., \& Montgomery, A. (1990). Family caregivers and limitations in social activities. Research on Aging, 12 (1), 72-101. 
Mittleman, M.S., Ferris, S.H., Shulman, E., Steinberg, G., \& Levin, B. (1996). A family intervention to delay nursing home placement of patients with Alzheimer disease: A randomized controlled trial. Journal of the American Medical Association, 276 (21), 1725-31.

Novak, M., \& Guest, C. (1989). Application of a multidimensional caregiver burden inventory. Gerontologist, 29 (6), 798-803.

Oktay, J.S., \& Volland, P.J. (1990). Post-hospital support program for the frail elderly and their caregivers: A quasi-experimental evaluation. American Journal of Public Health, 80 (1), 39-46.

Olson, D., Russell, C., \& Sprenkle, D. (1983). Circumplex model VI: Theoretical update. Family Process, 22, 69-83.

Ory, M.G., Williams, T.F., Emr, M., Lebowitz, B., Rabins, P., Salloway, J., Sluss-Radbaugh, T., Wolff, E., \& Zarit, S. (1985). Families, informal supports, and Alzheimer's disease. Research on Aging, I (4), 623-644.

Pariante, C.M. (1997). Chronic caregiving stress alters peripheral blood immune parameters: The role of age and severity of stress. Psychotherapy and Psychometrics, 66 (4), 19-207.

Pearlin, L.I. (1992). The careers of caregivers. Gerontologist, 32 (5), 647.

Pfeiffer, E. (1975). A short portable mental status questionnaire for the assessment of organic brain deficit in elderly patients. Journal of the American Geriatrics Society 23 (10), 433-441.

Radloff, L. S. (1977). The CES-D Scale: A self report depression scale for research in the general population. Applied Psychological Measurement, 1 (3), 365-401. 
Rankin, E.D. Haut, M.W. \& Keefover, R.W. (1992). Clinical assessment of family caregivers in dementia. Gerontologist, 32 (6), 813-821.

Reis, M.F., Gold, D.P., Andres, D., \& Markiewicz, D. (1994). Personality traits as determinants of burden and health complaints in caregiving. International Journal of Aging and Human Development, 39 (3), 257-271.

Semple, S.J. (1992). Conflict in alzheimer's caregiving families: Its dimensions and consequences. Gerontologist, 32 (5), 648-655.

Severson, M.A., Smith, G.E., Tangalos, E.G., Petersen, R.C., Kokmen, E., Ivnik, R.J., Atkinson, E.J., \& Kurland, L.T. (1994). Patterns and

predictors of institutionalization in community-based dementia patients. Journal of the American Geriatrics Society, 42 (2), 181-185.

Skaff, M.M., \& Pearlin, L.I. (1992). Caregiving: Role engulfment and the loss of self. Gerontologist, 32 (5), 656-664.

Smilkstein, G., Ashworth, C., \& Montano, D. (1982). Validity and reliability of the Family APGAR as a test of family function. Journal of Family Practice, 15 (3), 303-311.

Smith, H.D. (1993). Assessment and evaluation: An overview. In H. Hopkins \& H. Smith (Eds.), Willard and Spackman's occupational therapy (8th ed., pp. 169-172). Philadelphia: J.B. Lippincott.

Stephens, M. A. P., \& Zarit, S. H. (1989). Symposium: Family caregiving to dependent older adults: Stress, appraisal, and coping. Psychology and Aging, 4 (3), 387-388.

Stull, D.E., Kosloski, K., \& Kercher, K. (1994). Caregiver burden and generic well-being: Opposite sides of the same coin? Gerontologist, 34 (1), 88-94. 
Versluys, H.P. (1993). Family influences. In H. Hopkins \& H. Smith (Eds.), Willard and Spackman's occupational therapy (8th ed., pp. 163-164). Philadelphia: J.B. Lippincott.

Vitaliano, P. P., Young, H. M., \& Russo, J. (1991). Burden: A review of measures used among caregivers of individuals with dementia. Gerontologist, 31 67-75.

Vitaliano, P. P., Russo, J., Young, H. M., Becker, J., \& Maiuro, R. D. (1991). The screen or caregiver burden. Gerontologist, 31 (1), 76-83.

Walker, A. J., Acock, A. C., Bowman, S. R., \& Li, F. (1996). Amount of care given and caregiving satisfaction: A latent growth curve analysis. Journal of Gerontology: Psychological Sciences, 51B (3), 130-142.

Walker, A. J., Shin, H., \& Bird, D. N. (1990). Perceptions of relationship change and caregiver satisfaction. Family Relations, 39 (2), 147-152.

Winslow, B.W. (1997). Effects of formal supports on stress outcomes in family caregivers of Alzheimer's patients. Research in Nursing and Health, 20 (1), 27-37.

Zarit, S. H., Reever, K., \& Back-Peterson. J. (1980). Relatives of the impaired elderly: Correlates of feelings of burden. Gerontologist, 20 (6), 649-655. 
APPENDIX A 
ID \#

\section{The Role of Occupational Therapists with Caregivers}

Thank you for agreeing to complete this survey of OT's role of caregiving with the elderly. Please give only one answer to each question, and answer all questions. Your responses will remain anonymous. Please return by December $23^{\text {rd }}, 1997$.

\section{Screening Questions:}

1. I am an occupational therapist who is currently working in aging. Yes No

2. At least $25 \%$ of my work as an OT involves direct patient practice/contact.

Yes _ No

**If you have answered "NO" to either of the above questions, you do not need to complete this questionnaire. Please return the uncompleted questionnaire in the addressed, postage-paid envelope so that we do not send you a second mailing. Thank-you!

**If you have answered "YES" to both of the above questions, PLEASE complete the questionnaire and return it in the addressed, postage-paid envelope. It should take you less than 10 minutes to complete the questions. Thank-you!

\section{Demographic Information}

Directions: Please fill in the blanks, check, or circle the responses that best fit your practice situation.

1. How many years have you been employed as an OT in direct contact with any type of patients?

(Please approximate "part-time" employment to full time equivalent.)

I have been employed approximately years in direct patient care.

2. How many years have you been employed as an OT in direct contact with elderly patients? (Again, please approximate full-time equivalent.)

I have been employed approximately years in direct patient care with elderly patients.

3. Which of the following best describes your current place of employment as an OT?
(1) Skilled Nursing Facility
(2) Hospital
(5) Extended Care Facility
(3) Retirement Village
(4) Home Health
(6) Outpatient Facility
(7) ACLF (Adult Congregate Living Facility)
(8) Other

4. What is the highest degree you have earned in occupational therapy?
(1) Bachelors
(2) Masters
(3) Doctorate

5. What is the highest degree you have earned in any field?
(1) Bachelors
(2) Masters
(3) Doctorate

6. In which region of the country do you currently practice?
(1) Northeast
(2) Middle Atlantic
(4) Northwest
(3) Southeast
(5) Midwest
(6) Southwest 
7. With which ethnic/racial group do you most identify? (Check only one.)
(1) Black/African-American
(2) Hispanic/Latino/Latina
(5) Native American or Alaskan Native
(3) Asian-American or Pacific Islander
(6) White
(4) Asian (e.g. Filipino, Indian, Chinese)
(7) Multiracial
(8) Other

8. In which of the following activities relating to caregiving of the elderly do you participate professionally? (Check all that apply. Do not include activities related to personal caregiving.)

(1) Discharge planning with families

(4) Home evaluations

(2) Patient/caregiver education

(5) Environmental assessment/modification

(3) Support group participation

\section{Section II}

Since OTs use both informal and formal methods of assessment, we are interested in both methods that you may use with caregivers.

9. Which, if any, of the following informal methods of assessing the caregiver do you use?

(Check all that apply.)

(1) Observation of the caregiver

(2) Direct questioning/discussion with the caregiver

(3) Information from other professionals

(4) Checklists

(5) Other (please list)

(6) I do not informally assess caregivers for the following reason(s)

\section{Section III}

Since there is no universally accepted assessment tool for caregivers of the elderly, please indicate below which you use, if any.

10. Which, if any, of the following formal methods of assessing the caregiver do you use? (Check all that apply.)

(1) Global assessments (assessments which yield a single score even if they measure more than one domain)

(2) Multidimensional assessments (assessments which yield more than one score and measure more than one domain or attribute)

(3) Assessments created by using sections of existing assessments

(4) Facility created assessment

(5) Other (please list)

(6) I do not formally assess caregivers for the following reason(s) 


\section{Section IV}

The following are a sampling of some of the published assessments that might be used with a caregiver. Please use the following scale to indicate the frequency with which you use each of the following assessment tools. Circle the letter or number that best represents you and your specific situation.

Unfamiliar With

Assessment/Author Never Seldom Occasionally Frequently Always

$\begin{array}{llllllll}\text { Assessment } & \mathrm{U} & 1 & 2 & 3 & 4 & & 5\end{array}$

Family APGAR

(Smilkstein, Ashworth, \& Montano, 1982)

Friends APGAR $\mathrm{U}$ U 1 23 $4 \quad 5$

(Smilkstein, Ashworth, \& Montano, 1982)

Zarit Burden Interview (ZBI)

(Zarit, Reever, \& Bach-Peterson, 1980)

Caregiver Burden Interview (CBI) (Novak \& Guest, 1989)

U

U $\quad 1 \quad 2$

23

4 5

Cost of Care Index $(\mathrm{CCl})$

$\mathrm{U}$

12

$\begin{array}{lll}2 & 3 & 4\end{array}$

$4 \quad 5$

(Kosberg \& Cairl, 1986)

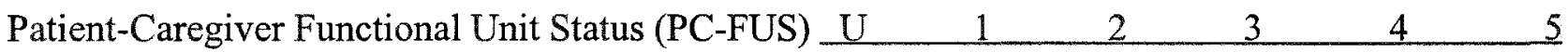
(Fredman \& Daly, 1997)

Screen for Caregiver Burden (SCB)

12 23 $3 \quad 4$ 5 (Vitaliano, Russo, Young, Becker, \& Maiuro, 1991)

Beck Depression Inventory (BDI) $\mathrm{U}$ 1 2 3 4 5 (Beck, Ward, \& Mendelson, 1961)

Center for Epidemiological Studies Depression Scale (CES-D) U 2 3 4 5 (Radloff, 1977)

Caregiver Hassles Scale (CHS) $\mathrm{U}$ 1 2 3 4 5 (Kinney \& Stephens, 1989)

Other (please list) 


\section{Section V}

\section{Managed Care}

For each situation listed below, please place a check in the column which best describes the effect managed care has had on your practice.

\section{Situation}

Efficiency of OT practice with caregivers/family

Quality of OT practice with caregivers/family

Amount of time with other professionals about caregivers and family

Amount of time with family/ friends of elderly patients
Situation No Effect Positive Effect Negative Effect Not Applicable 